\title{
Reflection tomography by depth warping: A case study across the Java trench
}

\author{
Yueyang Xia ${ }^{1}$, Dirk Klaeschen ${ }^{1}$, Heidrun Kopp ${ }^{1,2}$, Michael Schnabel ${ }^{3}$ \\ ${ }^{1}$ Dynamics of the Ocean Floor, GEOMAR, Helmholtz Centre for Ocean Research Kiel, Kiel, 24148, Germany \\ $5 \quad{ }^{2}$ Department of Geosciences, Kiel University, Kiel, 24118, Germany \\ ${ }^{3}$ Bundesanstalt für Geowissenschaften und Rohstoffe (BGR), Stilleweg 2, 30655 Hannover, Germany
}

Correspondence to: Yueyang Xia (yxia@geomar.de)

Abstract. Accurate subsurface velocity models are crucial for geological interpretations based on seismic depth images.

10 Seismic reflection tomography is an effective iterative method to update and refine a preliminary velocity model for depth imaging. Based on residual move-out analysis of reflectors in common image point gathers an update of the velocity is estimated by a ray-based tomography. To stabilize the tomography, several preconditioning strategies exist. Most critical is the estimation of the depth error to account for the residual move-out of the reflector in the common image point gathers. Because the depth errors for many closely spaced image gathers must be picked, manual picking is extremely time-consuming,

15 human biased, and not reproducible. Data-driven picking algorithms based on coherence or semblance analysis are widely used for hyperbolic or linear events. However, for complex-shaped depth events, pure data-driven picking is difficult. To overcome this, the warping method named Non-Rigid Matching is used to estimate a depth error displacement field. Warping is used, e.g., to merge photographic images or to match two seismic images from time-lapse data. By calculating the displacements between an offset to its neighbouring offset in the common image point domain, a locally smooth-shaped displacement field is defined for each data sample. Depending on the complexity of the subsurface, sample tracking through the displacement field along predefined horizons or on a simple regular grid yields discrete depth error values for the tomography. The application to a multi-channel seismic line across the Sunda subduction zone offshore Lombok island, Indonesia, illustrates the approach and documents the advantages of the method to estimate a detailed velocity structure in a complex tectonic regime. By incorporating the warping scheme into the reflection tomography, we demonstrate an increase in

25 the velocity resolution and precision by improving the data-driven accuracy of depth error picks with arbitrary shapes. This approach offers the possibility to use the full capacities of tomography and further leads to more accurate interpretations of complex geological structures. 
https://doi.org/10.5194/se-2021-40

Preprint. Discussion started: 14 April 2021

(c) Author(s) 2021. CC BY 4.0 License.

\section{Introduction}

Reflection tomography and pre-stack depth migration of multi-channel seismic reflection (MCS) data have evolved into standard seismic data processing routines in recent decades, owing to the rapid development of CPU performance and the effective adaption of seismic data processing software. Pre-stack depth migration (PSDM) is the algorithm of choice in reflection seismology to properly image steeply dipping reflectors while accounting for non-hyperbolic move-out caused by lateral velocity variations (Yilmaz, 2001; Jones et al., 2008) and thus is applied in tectonically and structurally complex geological settings in 2-D and 3-D migration strategies (Collot et al., 2011; Han et al., 2017; Li et al., 2018; Shiraishi et al., 2019). However, the quality of subsurface imaging depends on the seismic velocity model that is used for the migration. An exact determination of the velocity field is thus crucial to retrieve an optimal subsurface image. As is well known, PSDM may also be used as a velocity estimation tool to retrieve interval velocities by performing velocity analysis on selected locations using depth focusing error analysis (Audebert and Diet, 1990; MacKay and Abma, 1992) or hyperbolic residual move-out correction on common image point (CIP) gathers followed by a simple vertical Dix inversion (Dix, 1955) at each location independently, to manually build a structural velocity model (Audebert et al., 1997). Manual picking, however, is not only time-consuming for seismic processors but may also lead to a subjective interpretation bias. In contrast, the velocity model design based on reflection tomography inverts all CIP locations simultaneously to update the velocity structure and yields a more complete solution (Stork, 1992; Kosloff et al., 1996). The general procedure for reflection tomography is to go into the pre-stack migrated CIP offset-domain and to measure the hyperbolic residual move-out of the depth misalignment (also called depth error) by manual picking or by automatic slowness scanning techniques (Hardy, 2003; Claerbout, 1992). Subsequently, the depth error is inverted to velocity changes to flatten the reflector signals over the entire offset range (Jones et al., 2008; Fruehn et al., 2008). For regions with a highly variable velocity, however, a more severe non-hyperbolic depth misalignment

50 becomes a common situation, especially with increasing source-to-detector distances. To guide the velocity changes along the subsurface structures, predefined horizons can be included during the picking procedure as preconditioning during a layerbased tomography (Riedel et al., 2019). An overview of the model building techniques can be found in Jones (2003).

An established processing flow for reflection tomography of MCS data includes the determination of an initial P-wave velocity field, multiple attenuation with adaptive subtraction (Verschuur et al., 1992; Guitton and Verschuur, 2004), Kirchhoff

55 PSDM, depth error estimation of CIP offset-gathers, followed by ray-based tomographic inversion to update the velocity field (Fig. 1). In general terms, the tomographic inversion identifies an optimal model which explains the observed input data (Bishop et al., 1985). An equivalent approach is the migration velocity analysis technique which is based on forward and reverse ray-based propagation of travel times to find a velocity model that minimizes the CIP depth error (Van Trier, 1990). While the Dix inversion strips off the layers from top to bottom in a flat-layer approach, the ray-based tomography accounts

60 for dipping layers and lateral velocity changes within the streamer length (Jones, 2010). Both the pre-stack depth migration and depth tomography algorithms rely on the definition of the initial seismic velocity field in the subsurface. The starting velocity model is normally retrieved from seismic data semblance velocity analysis (Neidell and Taner, 1971) of either non- 
https://doi.org/10.5194/se-2021-40

Preprint. Discussion started: 14 April 2021

(c) Author(s) 2021. CC BY 4.0 License.

(c) (1)

migrated CMP gathers, pre-stack time migrated CIP analyses, wide-angle travel-time tomography, or full-waveform inversions if no additional in situ information is available (Gras et al., 2019; Górszczyk et al., 2019). By relating changes of the CIP depth errors to changes in velocities along source-receiver rays in the direction normal to the local reflector dip, a new velocity can be calculated to minimize the CIP depth errors. To solve the general non-linear inverse tomographic problem, the velocity error is gauged iteratively, inverted, and updated as depicted by the loop in Fig. 1.

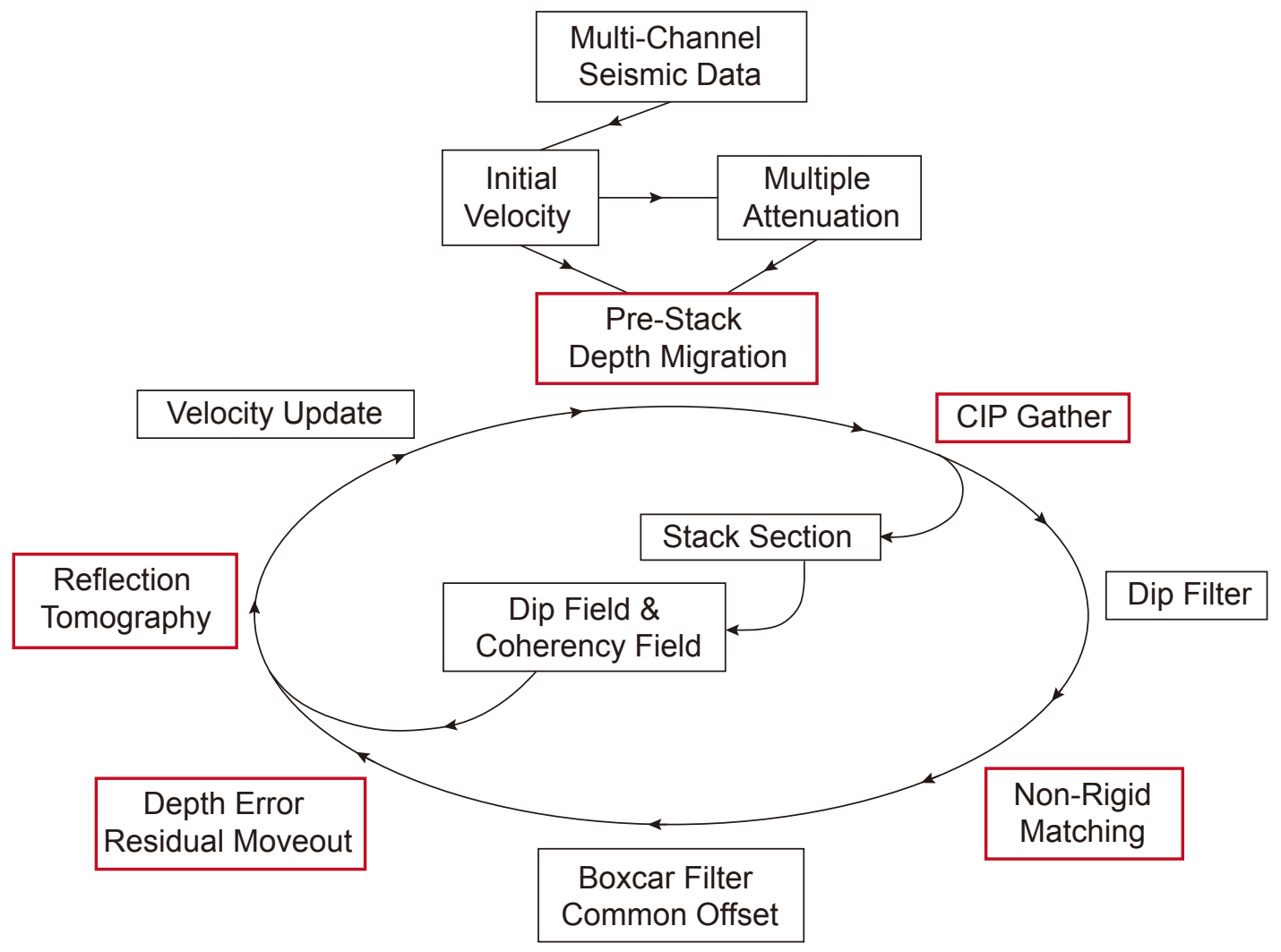

Figure 1. Processing scheme using Non-Rigid Matching in reflection tomography to update the velocity field during pre-stack depth migration of multi-channel seismic reflection data. The main processing steps are marked in red.

Good quality of imaging and of the tomographic result must fulfil both the conditions of accuracy and precision of the input information, which describe the trueness and density of the input depth picks of the depth error (Jones, 2003). The precision may be improved by setting a smaller vertical and lateral picking interval to maximize the reliability of the tomography. On the other hand, accuracy is strongly limited by signal interference, background noise, side echoes, and accurate depth error information. To circumnavigate these issues and increase the picking accuracy and precision, we applied an innovative warping technique called "Non-Rigid Matching" (NRM). By calculating the depth error shift of seismic trace samples by comparing successively neighbouring traces along the complete offset of closely spaced CIP gathers, we improve the accuracy and 
https://doi.org/10.5194/se-2021-40

Preprint. Discussion started: 14 April 2021

(c) Author(s) 2021. CC BY 4.0 License.

(c) (i)

precision of the depth error estimation without any hyperbolic assumption or predefined depth horizons of the subsurface structure.

Here we present the NRM technique for the depth error estimation as a pure data-driven automatic picking method. We demonstrate the advantages and limitations of the NRM method using a synthetic gather. We then apply a combination of NRM with reflection tomography to field data of pre-stack depth migrated seismic sections from the Sunda convergent margin offshore Lombok island, Indonesia. The profile is characterized by an accretionary prism of strongly folded sediment with limited reflector continuity, which makes manual velocity estimation extremely challenging.

\section{Non-rigid and warping matching techniques}

The non-rigid matching (NRM) or "Warping" methods are computer-based image matching technologies that aim to estimate a flow pattern (vector displacement in 3-dimensions) of a sequence of images with additional smoothness constraints (Horn and Schunck, 1981; Wolberg, 1990). Compared to a rigid matching like translation, rotation, or even affine transformation, NRM is developed to handle situations when the transformation is non-linear, or any of the images suffer from the noise of

90 independent parts (Pappu et al., 1996). The benefit of NRM regarding the non-linear transformation substantially improves seismic imaging and inversion methods through matching and tracking horizontal and vertical displacements of seismic events with high accuracy in the depth and time domains.

NRM or warping applications were first introduced for 3D time-lapse seismic data by comparing two seismic cubes acquired at different acquisition times with special focus of depth formation changes resulting from hydrocarbon production (e.g.,

95 Rickett and Lumley, 2001; Aarre, 2008; Tomar et al., 2017). The image displacement warping method of Hall (2006) estimates a full 3D local vector deviation employing an iterative search of maximum correlation using a deformable mesh for sensitivity and quality analysis, whereas Hale $(2009,2013)$ based his dynamic image warping (DIW) on 1D cross-correlation optimization schemes in each dimension to estimate the vector displacements. By solving a set of $1 \mathrm{D}$ equations and separately including spectral whitening and a Gaussian low-pass filter, a stable 3D solution is achieved iteratively by minimizing the difference of the reference and the current wavefield corrected by the estimated displacements. In contrast, the NRM method introduced by Nickel and Sønneland (1999) uses 1D Taylor expansions for each vector component, which are separately solved for each dimension to converge to a 3D solution by minimizing the difference of the reference section and the current wavefield corrected by the estimated displacements like by the warping method of Hale (2009) (Aarre, 2006; Aarre, 2008). To stabilize the results, additional constraints are implemented, e.g., bandlimited application, smoothing for spatial continuity, and avoiding vertical shifts that would swap neighbouring depth samples.

An application of NRM for the vertical displacement calculation of neighbouring offset traces of a current CIP gather requires a reference CIP gather, similar to a time-lapse application. This can be achieved by duplicating the current gather and shifting the traces laterally to smaller offsets by one offset position to form the reference gather. As neighbouring traces of a CIP gather show a strong similarity of the waveform and amplitude without spatial aliasing, the NRM can then be used to estimate the 
https://doi.org/10.5194/se-2021-40

Preprint. Discussion started: 14 April 2021

(c) Author(s) 2021. CC BY 4.0 License.

(c) (i)

110 vertical displacement between the current gather and the reference gather, which corresponds to the vertical smooth displacements between neighbouring traces of the current CIP gather without any physical assumptions. In this way, the application of NRM for CIP gather depth error alignment overcomes the limitation of residual move-out estimations inherent in conventional semblance scanning of predefined functions like linear, parabolic, or even higher order curvatures (Sripanich et al., 2017). A recursive application of the depth variant static displacements for each trace will flatten all events of the current

115 CIP gather.

Generally, we introduce here a relative referenced scheme that always compares and calculates the relative displacement shift (also known as the event slope dip) between neighbouring traces, rather than comparing all traces to a near-offset reference trace as is commonly done in the conventional approach. With the existence of noise and independent events, the relative referenced NRM rejects possible outliers due to predefined smoothness constraints and determines an optimal spatial transformation for mapping one trace to the other while preserving a similar salient structure along the traces. The stability and compatibility of this application to high noise-level data are some of the main advantages of non-rigid matching compared to conventional semblance scanning.

A number of geophysical applications for pre-stack event tracking by the warping technique have been introduced in the scientific community in the last decade (e.g., Reiche and Berkels, 2018; Sripanich et al., 2020). The main objective of all these

125 applications is to efficiently define a reference trace or dataset and calculate the displacement shift from any trace to match the reference trace. The unique selection of the reference trace section depends on the individual purpose of the application. Reiche and Berkels (2018) sorted the migration data to common offset sections and selected the nearest offset gather as a reference section, and calculated the displacement from all other offset sections to the nearest one in order to calculate the move-out curvature and flatten the common-mid-point (CMP) gather. Sripanich et al. (2020) estimated the move-out dip slopes on 3D CMP gathers directly by a plane-wave destruction filter (Fomel, 2002).

\subsection{Synthetic Data Example}

For field MCS data, due to the complex subsurface structure and seismic acquisition geometry, as well as the anisotropic physical world, three main unique classified situations represent the main difficulties for analysing the residual move-out with the conventional semblance scanning. These situations are: (1) non-linear or non-parabolic curvature events; (2) two interfering

135 events; and (3) offset-dependent wavelet amplitude and frequency attenuation. Of course, some real data will show all these characters at the same time. Therefore, we analyse the non-rigid displacement calculation and residual move-out picking method on a synthetic gather based on these three extreme situations (Fig. 2).

In Fig. 2a, three sets of synthetic seismic sections are generated from top to bottom, which are first a symmetrical diffractionlike event, second two intersecting events with opposite polarity, and third a seismic event with an offset and amplitude varying wavelet and some non-linear local undulation. 

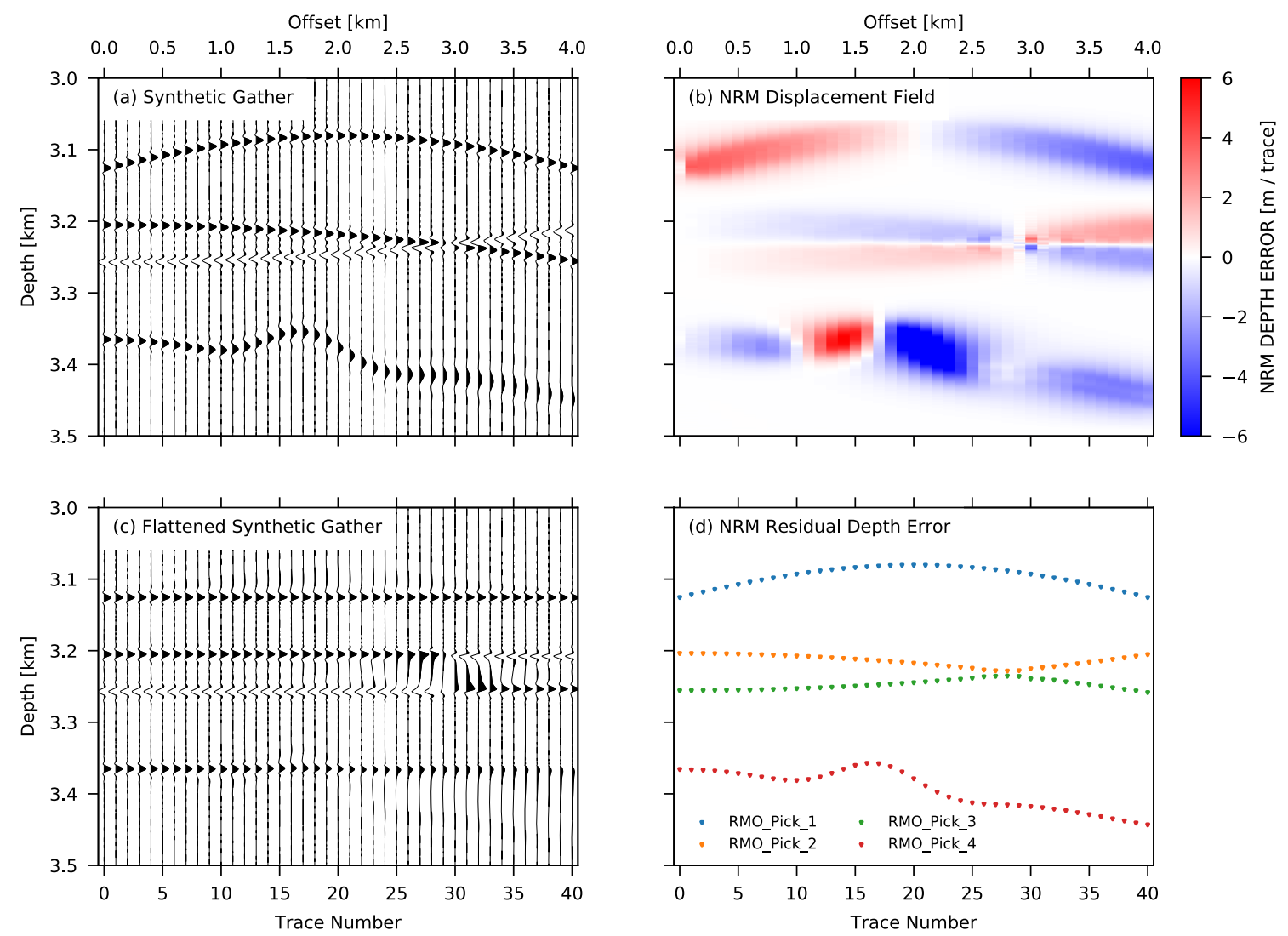

Figure 2. (a) Simulated complex geological situations that would be frequently seen in pre-stack depth migrated (PSDM) common-imagepoint (CIP) domain. A symmetrical diffraction, two interfering primaries with opposite polarity, and a non-linear local static undulation, including frequency versus offset signal variations. (b) The NRM displacement of gather (a) calculated from trace $n$ to the previous trace ( $n-1)$ for $n>1$. (c) Application of the displacement correction from (b) to the gather of (a). (d) Residual move-out picks calculated by recursive summation of the relative depth errors (b) at predefined depths to get the cumulative depth error.

Because the NRM displacement field in Fig. $2 b$ is calculated in a relative referenced scheme, the field contains relative dip displacements of a trace to its previous trace. The red colour of positive values in each trace shown in Fig. $2 \mathrm{~b}$ suggests that a corresponding trace sample in Fig. 2a should be shifted downward to match and align to its previous trace sample. Bluecoloured negative values require shifting in the opposite (i.e., upward) direction. A zero-displacement value appearing at the apex of the symmetrical diffraction events illustrates the fact that the dipping angle at this location of the event is zero. The NRM field of these three sets of synthetic sections follows the general local dip trend well. An application of the NRM field to flatten the synthetic gather requires a recursive depth variant correction. The NRM depth variant shifts of the first trace are 
https://doi.org/10.5194/se-2021-40

Preprint. Discussion started: 14 April 2021

(c) Author(s) 2021. CC BY 4.0 License.

applied to the first trace and all following traces. The NRM depth variant shifts of the second trace are applied to the second trace and all following traces in the gather. This sequence repeats until the last trace is corrected.

The NRM flattened events by the recursive depth variant correction in Fig. 2c provide quality control of displacement calculation for these three special situations. Generally, the squeeze-and-stretch effect of the non-linear displacement correction is inevitable for a multi-trace gather, but as shown here, the displacement shift correction adequately dealt with most of the simulated examples. The first symmetrical diffraction events get optimally flattened, with no significant change of the wavelet shape. The third non-linear undulation with a wavelet variation effect is perfectly flattened at the peak amplitude, but here a strong wavelet stretch is visible. After the NRM displacement correction, the wavelets at mid offsets (1.5 to $2.5 \mathrm{~km})$ get squeezed, and the ones at far offsets ( 3.5 to $4.0 \mathrm{~km}$ ) get stretched. For a potential AVO analysis, additional vertical smoothing of the displacement field would be necessary to avoid the observed stretching effects. The crossing region of the two intersecting events gets flattened well but suffers from a significant stretch effect, which introduced substantial artificial lowfrequency energy between the two events between offset 2.5 and $3.5 \mathrm{~km}$. Due to the constraint that vertical shifts cannot swap neighbouring depth samples, a false event relation occurred beyond $3 \mathrm{~km}$ offset, as clearly seen on Fig. 2c by the opposite signal polarity along the two flattened events (between 3.2 and $3.27 \mathrm{~km}$ depth). As a result, in a final stacking procedure of this CIP gather, the NRM displacement correction will lead to wavelet stretching, squeezing artefacts, and destructive 170 summation.

Of importance for tomography is not the waveform, but only a correct depth error estimation along reflected events. To calculate the depth error, a recursive depth variant correction of the NRM field in Fig. $2 b$ by itself will be applied in the same way as it was used to flatten the seismic gather in Fig. 2c, resulting in a horizontal alignment of the displacement field. A cumulative summation of NRM displacement values along a predefined depth slice subtracted from the starting depth will

175 yield the desired depth error information for each trace, as shown in Fig. 2d. All residual move-out (RMO) depth error picks follow the amplitude peaks of the seismic events except for the " $\mathrm{X}$ " shaped interfering primaries. The NRM displacements are misled by the crossing point and switch to an event that should not be followed. This kind of "V" shape depth error information will undermine the reliability of the tomographic result. If these two interfering events are both primaries, some alternative options to deal with this situation are to either terminate permanently the current RMO-picks when intersecting the crossing

180 event or to terminate this picking procedure at the crossing point and start a new series of RMO-pick values again right after it, through to the end of the offset range. So, instead of only one, two series or branches of depth error RMO picks will be recorded and set as input information to the tomography. If these crossing events happen as a result of interfering noise like a surface-related multiple, then the interfering multiple reflections should be attenuated prior to NRM by a dip filter in the CIP gather (Fig. 1).

\subsection{Study area and MCS data pre-processing}

The multi-channel 2-D reflection seismic profile BGR06-313 that we use in three field examples was using a $3000 \mathrm{~m}$ long, 240 channel digital streamer with a group distance of $12.5 \mathrm{~m}$ at a towing depth of $6 \mathrm{~m}$. A two string G-Gun array of $3080 \mathrm{in}^{3}$ 
https://doi.org/10.5194/se-2021-40

Preprint. Discussion started: 14 April 2021

(C) Author(s) 2021. CC BY 4.0 License.

(50.8 1) volume with a nominal shot point distance of $50 \mathrm{~m}$ was used as a source across the southern Java trench in the southeastern part of the Sunda subduction zone (Lüschen et al., 2011) as part of the SINDBAD project during RV SONNE Cruise

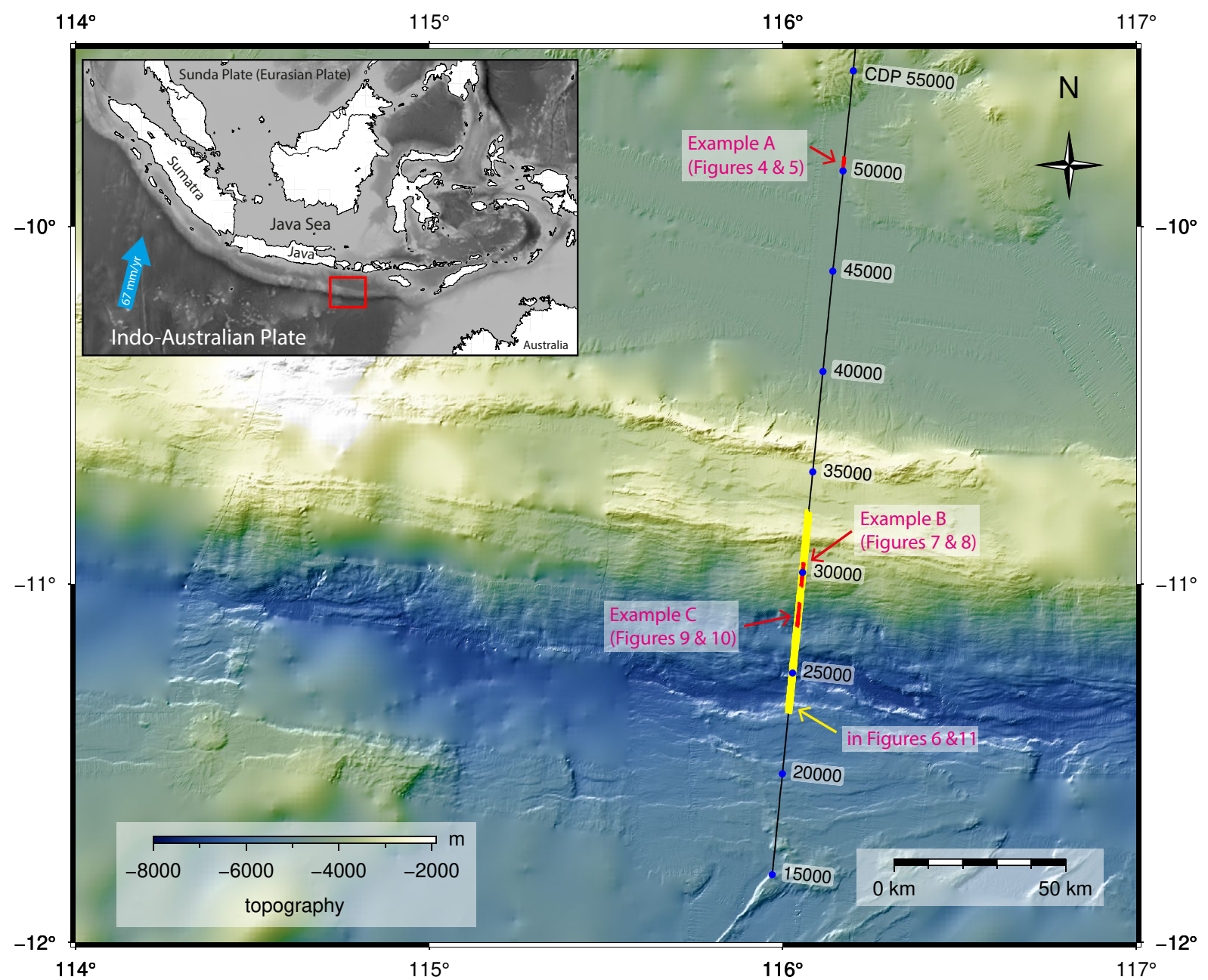

Figure 3. Map of the study area offshore Southern Java. The location of the multi-channel and collocated wide-angle seismic profile is shown by a black line. Three examples at locations A, B, and C (marked in red) of the NRM based velocity updating for the depth tomography and pre-stack depth migration result are discussed in detail. Example A is located at shallow depth with simple complexity, whereas examples $\mathrm{B}$ and $\mathrm{C}$ are crossing the subduction trench and accretionary wedge (yellow line) show high complex structures where standard velocity analyses mostly fail by discontinuous highly dipping structures.

The seafloor depth ranges from $1.5 \mathrm{~km}$ near the shore on the northern part of the line to $6.5 \mathrm{~km}$ in the deep-sea trench. Details of our seismic processing sequence are provided in Tab. 1. In preparation for the Kirchhoff PSDM, the multiple reflections have been attenuated using a free surface multiple prediction (Verschuur et al., 1992) followed by a frequency-split 2D adaptive 
Table 1. Seismic processing sequences and image grid sizes.

\begin{tabular}{|c|c|c|}
\hline \multicolumn{3}{|c|}{ Sequence Step Names } \\
\hline \multicolumn{3}{|c|}{ Normal and Nominal Geometry Establishment with CMP spacing of $6.25 \mathrm{~m}$} \\
\hline \multicolumn{3}{|c|}{ Anomalous and Random Noise Attenuation } \\
\hline \multicolumn{3}{|c|}{ Padding Interpolated Traces to Zero Offset } \\
\hline \multicolumn{3}{|c|}{ Interactive Velocity Analysis in Time Domain } \\
\hline \multicolumn{3}{|c|}{ Initial Time-domain Velocity building } \\
\hline \multicolumn{3}{|c|}{ Shot Interpolation for Aliasing Elimination (from $50 \mathrm{~m}$ to $12.5 \mathrm{~m}$ shot distance) } \\
\hline \multicolumn{3}{|c|}{ Surface-Related Multiple Prediction } \\
\hline \multicolumn{3}{|c|}{ Multiple Attenuation 1: Frequency-Split 2D Cascaded Adaptive Filter } \\
\hline \multicolumn{3}{|c|}{ Multiple Attenuation 2: Radon Dip Filter } \\
\hline \multicolumn{3}{|c|}{ Multiple Attenuation 3: Inside Mute and Amplitude Clipping } \\
\hline \multicolumn{3}{|c|}{ Kirchhoff Pre-stack Time Migration } \\
\hline \multicolumn{3}{|c|}{ Initial Depth Domain Velocity Building (Merge with Wide-angle model) } \\
\hline \multicolumn{3}{|c|}{ Kirchhoff Pre-stack Depth Migration (Initial) } \\
\hline \multicolumn{3}{|c|}{ Common Image Point (CIP) Gather Sorting } \\
\hline \multicolumn{3}{|c|}{ Pre-filtering for NRM Calculation } \\
\hline \multicolumn{3}{|c|}{ NRM Displacement Field Calculation } \\
\hline \multicolumn{3}{|c|}{ Pre-stack Depth Migrated Gather Residual Move-out Calculation from NRM Field } \\
\hline \multicolumn{3}{|c|}{ Depth Migrated Stack Section Dip Field and Coherency Estimation } \\
\hline \multicolumn{3}{|c|}{ Depth Tomography } \\
\hline \multicolumn{3}{|c|}{ Update the Tomography Model Properties that will Minimize the CIP-gather RMO } \\
\hline \multicolumn{3}{|c|}{ Kirchhoff Pre-stack Depth Migration with CIP-gather output } \\
\hline \multicolumn{3}{|c|}{ Image Grid Sizes } \\
\hline Image & Inline X (m) & Depth Z (m) \\
\hline Migration Grid & 6.25 & 4 \\
\hline Velocity Grid & 50 & 16 \\
\hline CIP Gather Increment & 100 or 200 & - \\
\hline CIP Gather Offsets & $105-3150$, incr. 100 & - \\
\hline
\end{tabular}

Table 2. Successive smoothing scale length reduction applied for each iteration of the depth tomography.

\begin{tabular}{|l|l|l|l|}
\hline $\begin{array}{c}\text { Application } \\
\text { Sequence }\end{array}$ & $\begin{array}{l}\text { Application Depth } \\
\mathbf{Z}(\mathbf{m})\end{array}$ & $\begin{array}{l}\text { Scale length } \\
\mathbf{X}(\mathbf{m})\end{array}$ & $\begin{array}{l}\text { Scale length } \\
\mathbf{Z}(\mathbf{m})\end{array}$ \\
\hline 1. & 0 & 10000 & 1008 \\
\hline & 13000 & 13000 & 1008 \\
\hline 2. & 0 & 5850 & 720 \\
\hline & 13000 & 7626 & 720 \\
\hline 3. & 0 & 3450 & 512 \\
\hline & 13000 & 4485 & 512 \\
\hline 4. & 0 & 2000 & 352 \\
\hline & 13000 & 2600 & 352 \\
\hline 5. & 0 & 1150 & 240 \\
\hline & 13000 & 1538 & 240 \\
\hline 6. & 0 & 700 & 160 \\
\hline & 13000 & 910 & 160 \\
\hline
\end{tabular}


https://doi.org/10.5194/se-2021-40

Preprint. Discussion started: 14 April 2021

(c) Author(s) 2021. CC BY 4.0 License.

least-square subtraction (Robinson and Treitel, 2000; Guitton and Verschuur, 2004), and a Radon transform dip filter (Hampson, 1986). The initial velocity model for the reflection depth tomography was merged from a velocity tomographic inversion of a collocated 2-D refraction seismic line covered by 46 ocean bottom seismometers (OBS) with a spacing of $6 \mathrm{~km}$ (Planert et al., 2010) and a manually estimated velocity model for the near seafloor structure. Previous trials by semblance velocity analysis picking in CIP gathers followed by Dix inversion gave unsatisfying results to construct a detailed interval velocity model after pre-stack time migration as well as pre-stack depth migration. A CIP increment of 500 (3125 m), with a CDP distance of $6.25 \mathrm{~m}$, yielded no spatial and depth consistent velocity model, especially for the lower trench slope because of small reflection segments with varying dip. As a consequence, the approximated velocity at shallow depth was additionally smoothed before merging with the wide-angle velocity model and was used as the initial velocity for the NRM-tomography.

215 Each iteration of the tomography in the processing loop of Fig. 1 started with the longest scale length over the complete depth range (Tab. 2). During a maximum of six iterations, the smoothing scale length was successively reduced by one scale length for each subsequent iteration, e.g., first iteration only first application sequence, second iteration first application followed by second application sequence, etc. (see Tab. 2). To avoid velocity changes during the tomography in the water column, which would result in depth changes of the seafloor, a hybrid model was defined containing the seafloor as the only predefined horizon with the preconditioning not to update the layer above. The regional depth variant water velocity used was extracted from the Climatological Atlas of the World Ocean MB-System (Levitus, 1982). An initial depth slice increment of $50 \mathrm{~m}$ for the residual depth error picks tracking through the NRM displacement field was depth adjusted based on the maximum and minimum threshold semblance values by parabolic scanning along offsets of the CIP gather. To balance the quality of the picks, the spatial coherency of the depth migrated structure was applied as an additional weight function for the picks.

In the following, we show three data examples in different structural settings with a comparison of initial and final results of the velocity model, the PSDM section, and the NRM displacement field, and the spatial coherence field of the final PSDM section. To document the change in the CIP-gather domain, we additionally compare initial and final CIP gathers, the calculated NRM displacement fields, the residual depth error picks, as well as on overlay display with the CIP gather and the depth error picks.

\subsection{Sediment Basin NRM-Tomography}

The first field data example, "Example A," at the northern end of the profile (Fig. 3), is a shallow sediment basin with layered interfaces and continuous reflectivity and represents an optimal site to obtain a reliable velocity model in a 2-D multi-channel seismic survey. A CIP-gather increment of $32(200 \mathrm{~m})$ was analysed along the profile with the NRM method. In total, five iterations of tomography loops (Fig. 1) were applied to this data example. An enlarged view of the initial velocity model ranging from CDP 46700 to CDP 50800 is displayed in Fig. 4a. The resulting initial Kirchhoff pre-stack depth migration (Fig. 4c) retrieves a coherent image of the shallow sedimentary portion, while the energy in the deeper part close to the basement is not very well collapsed, resulting in a series of over-migrated events. The displayed reflector dip field (Fig. 4e) and coherency field (Fig. 4f) are extracted from the final migration section. 
https://doi.org/10.5194/se-2021-40

Preprint. Discussion started: 14 April 2021

(C) Author(s) 2021. CC BY 4.0 License.
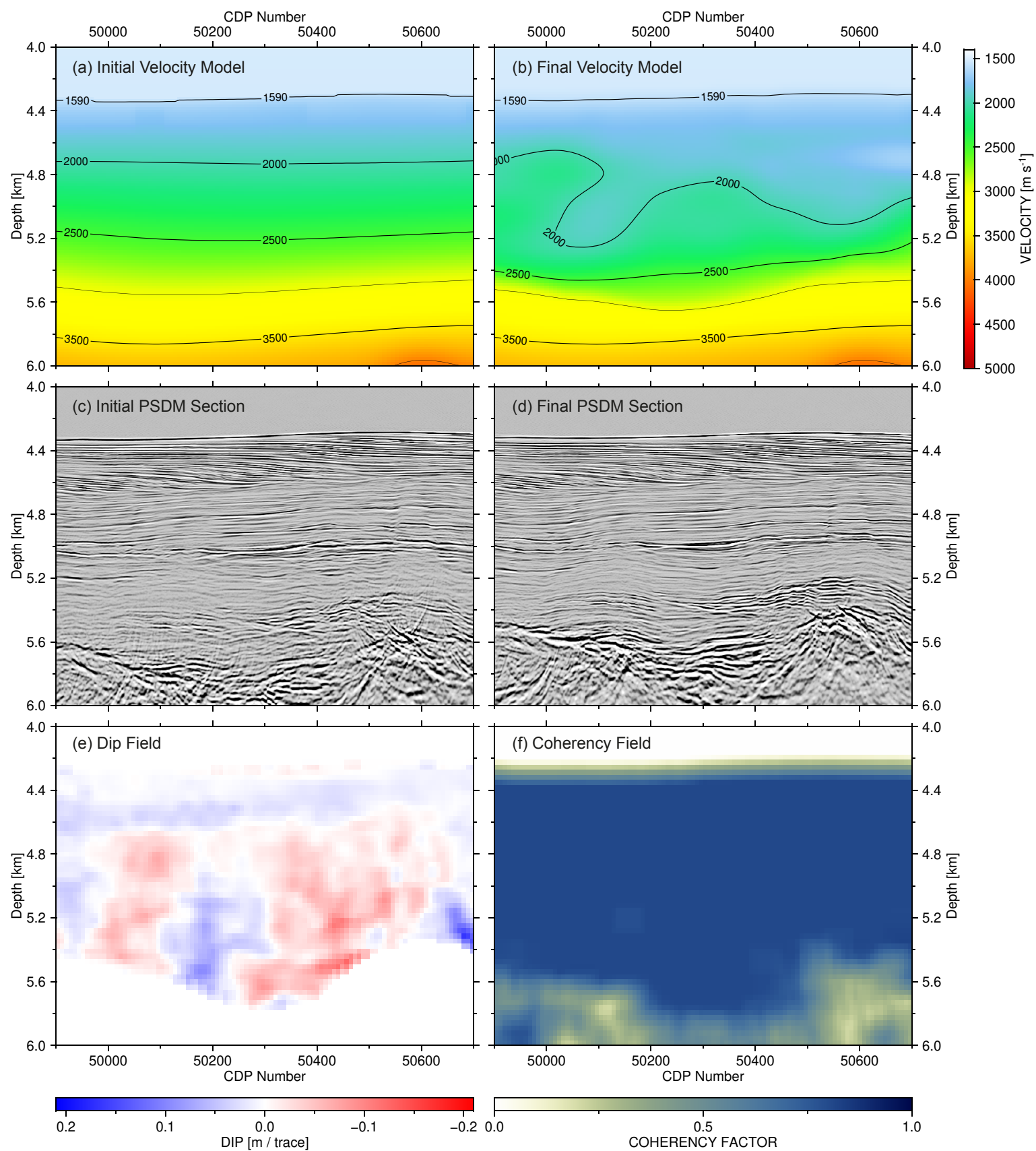

240 Figure 4. Depth tomography example A from Fig. 3, with CDP ranging from 46700 to 50800. (a) Initial velocity model merged from velocity analysis and wide-angle refraction tomography. (b) Final velocity model after five iterations of NRM based depth tomography and PSDM. (c) PSDM result based on the initial velocity model. (d) PSDM result based on the final velocity model. (e) Reflector dip field calculated from the final PSDM result. (f) Reflector coherency field calculated from the final PSDM result. Notice that 'migration smile' artefacts at a depth of $5.6 \mathrm{~km}$ in (c) get significantly reduced in the final PSDM result (d). 
https://doi.org/10.5194/se-2021-40

Preprint. Discussion started: 14 April 2021

(c) Author(s) 2021. CC BY 4.0 License.

(c) (1)
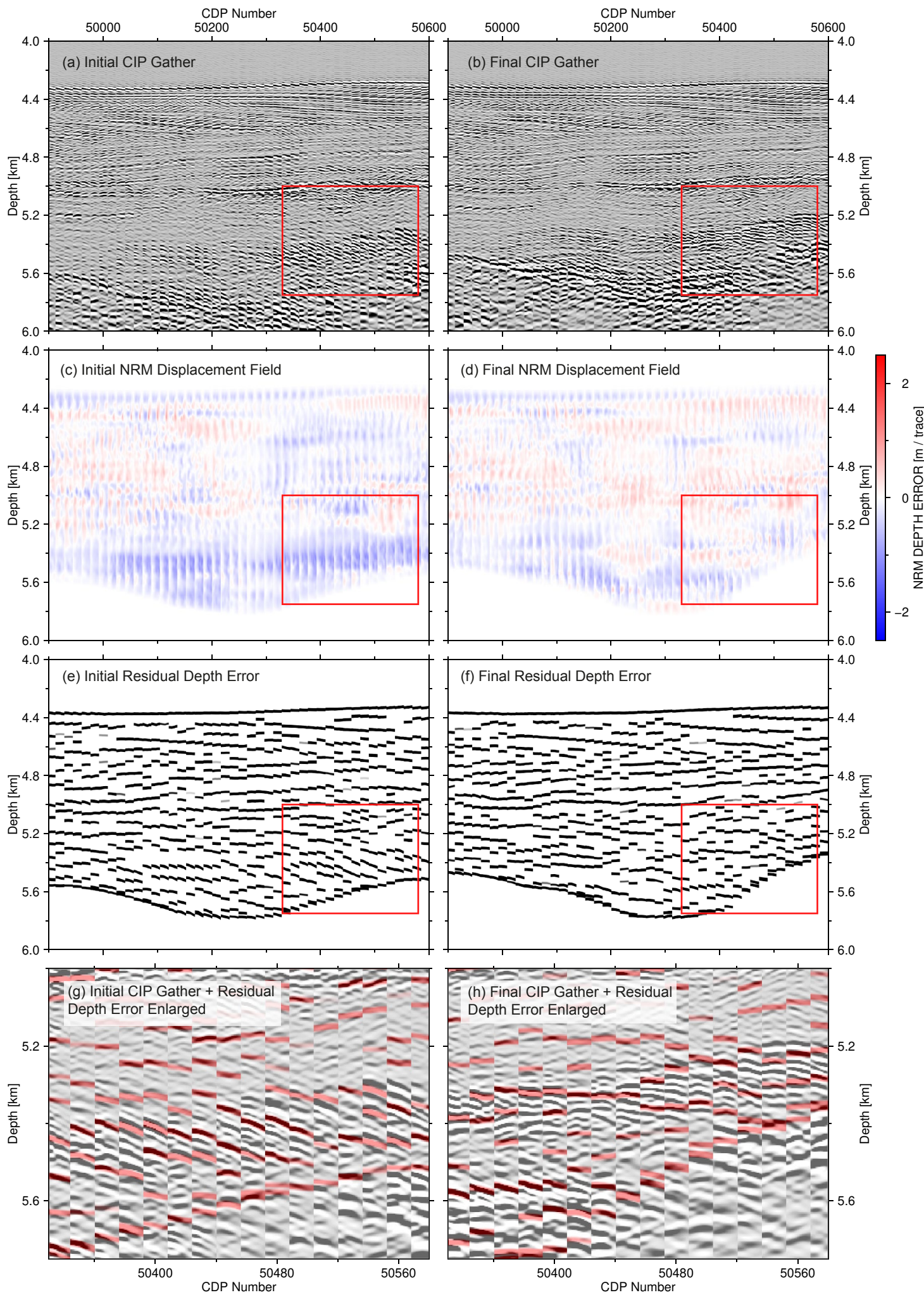
https://doi.org/10.5194/se-2021-40

Preprint. Discussion started: 14 April 2021

(c) Author(s) 2021. CC BY 4.0 License.

(c) (i)

Figure 5. NRM velocity updating of Fig. 4 in CIP domain. (a) CIP gathers based on the initial velocity model. (b) CIP gathers based on final velocity model. (c) Initial NRM depth shifts in the CIP domain. (d) Final NRM depth shift in CIP domain. (e) RMO picks calculated from the initial NRM displacement field. (f) RMO picks calculated from the final NRM depth displacement field. Notice that the distinct area of velocity overestimation in the red rectangle in panel (c) has been substantially reduced after the tomography (d). CIP gathers (e) and (f) of the red rectangle from (c) and (d) respectively overlaid by RMO picks. Strong dipping events in the initial CIP gather (g) have been flattened after the final iteration $(\mathrm{h})$.

The reflector dip is used for the ray propagation direction during the tomography, and the coherency field is used as an additional weighting of RMO depth error picks in spatial coherent subsurface areas. The two attribute fields were recalculated for each iteration of the tomography loops (Fig. 1). After five iterations of the NRM based depth tomography and Kirchhoff PSDM, the reflection energy is much better collapsed and shows sharper and more continuous signals, especially in the deeper part between 5.2-5.6 km (Fig. 4d). Furthermore, the final velocity model (Fig. 4b) displays lateral velocity variations that mimic the form of the base of the sediment basin. This is well demonstrated by the $3000 \mathrm{~m} \mathrm{~s}^{-1}$ velocity contour that mimics the shape of the boundary between the highly reflective basement (below) and the less reflective but more laterally continuous reflections of the sedimentary sequence (above).

Moving into the pre-stack CIP domain, a series of CIP gathers ranging from CDP 46700 to 50800 (same profile range as in Fig. 4) are selected and displayed in Fig. 5a with an increment of $32(200 \mathrm{~m})$. A dip filter is applied to the gathers to eliminate the extreme dipping events and migration noise. The NRM field in Fig. 5c shows the initial relative displacement values for each data sample. The information below the basement is muted by a digitized basement horizon. The distinct block of blue colour within the red rectangle in Fig. $5 \mathrm{c}$, at a depth of $5.0 \mathrm{~km}$ to $5.8 \mathrm{~km}$, illustrates a general velocity overestimation in the overlying sediment. The RMO depth error picks calculated from the NRM displacement field, as a data-driven automatic picking method without any assumption of its curvature, is the main input information for the tomography (Fig. 5e). Figures $5 \mathrm{~b}, 5 \mathrm{~d}$, and $5 \mathrm{f}$ show the final flattened CIP gather, NRM displacement field, and RMO depth error picks, respectively. Compared to the initial data, the updated events in the CIP gather become optimally flattened. The depth of the basement shifts upwards by $0.2 \mathrm{~km}$ due to the velocity reduction of the final model. In the final NRM field (Fig. $5 \mathrm{~d}$ ), the velocity overestimation error in the region of the red rectangle is substantially reduced. However, some residual move-out undulations from the initial to the final stage remain, as seen in detail in Fig. $5 \mathrm{~g}$ and $5 \mathrm{~h}$ from the CIP-gathers overlain with the RMO depth error curves. Ideally, the final NRM displacement field in Fig. 5d should have no NRM depth shift anymore, and all depth error picks should align horizontally. This can be achieved by an additional independent residual move-out correction for each CIP without the following tomography. The tomography finds only the solution that minimizes the depth error with respect to the smallest scale lengths (Tab. 2) used for the tomography. 
https://doi.org/10.5194/se-2021-40

Preprint. Discussion started: 14 April 2021

(C) Author(s) 2021. CC BY 4.0 License.
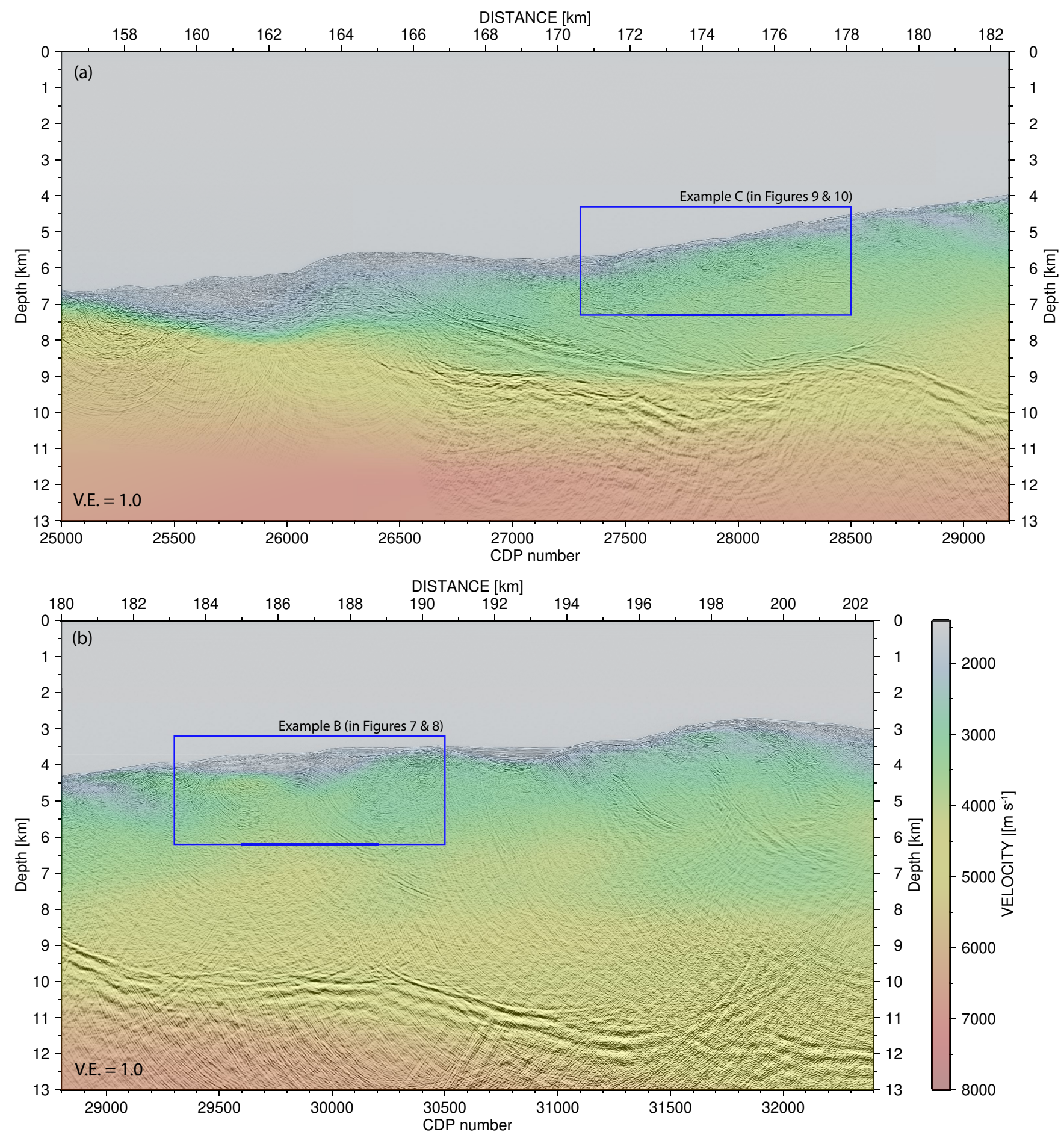

Figure 6. Depth migration stack section of six iterations depth tomography with final velocity model overlain. The location of the profile is illustrated in Fig. 3 as a yellow line. Rectangular boxes are discussed in the section on field data examples from the accretionary wedge. (a)

Data example C. (b) Data example B. 
https://doi.org/10.5194/se-2021-40

Preprint. Discussion started: 14 April 2021

(c) Author(s) 2021. CC BY 4.0 License.

(c) (i)

\subsection{Accretionary Wedge NRM Tomography}

In the following, the PSDM profile (location marked by the yellow line in Fig. 3) with the final velocity model overlain in Fig. 6 will be further analysed. Two data examples (Fig. 3, examples B and C, marked in red) in the blue rectangles within the accretionary wedge in Fig. 6 show distinct levels of complexity. The selected upper slope area is characterized by strongly folded continuous reflector sequences, whereas the lower slope area contains only short reflector segments with varying dip. The lack of coherent reflective signals in this highly deformed accretionary prism leads to a severe difficulty to accurately evaluate the residual move-out in the CIP gathers, especially if the spatial increment of manual gather picking is greater than the lateral dimensions of velocity structures to be resolved. As a consequence of the spatially complex reflectivity pattern, the automated CIP analyses were reduced to an increment of $16(100 \mathrm{~m})$ to achieve more redundancy of depth error estimations during six iterations of the tomography.

\subsubsection{Upper Slope NRM Tomography}

Our second field data example focuses on a sequence of thick sediment tilted by compressive deformation in the region marked by the blue rectangle example B in Fig. 6b. Figure 7 provides a detailed image of the PSDM section and velocity model from the initial and final stages. The final velocity (Fig. 7b) is significantly reduced compared to the initial velocity model (Fig. 7a) in the shallow part and significantly increased compared to the initial model at depths of 5.2-6.2 km. The reflector sequences of the anticline structure between CDP 29300 and 29500, from 4.0-4.4 km depth, are more continuous in the final image (Fig. 7d) than in the initial image (Fig. 7c), especially at the top of the anticline. The dip of the folded reflector sequence between CDP 29800 and 30100, above $4.8 \mathrm{~km}$, is more geologically realistic in the final image (Fig. 7d), where reflector dip increases steadily with increasing distance from the apex of the fold. By contrast, the initial image in this same region (Fig. 7c) shows an unrealistic abrupt change in dip near the apex of the fold.

Comparing the initial and final CIP gathers in Fig. $8 \mathrm{a}$ and $8 \mathrm{~b}$ inside the red rectangle, strong downward dipping reflections indicate the requirement to reduce the initial velocity significantly. The NRM displacement field in Fig. 8c provides a more quantitative view of this requirement, seen by the strong blue colour with more than $2 \mathrm{~m}$ depth error per trace distance. The calculated RMO picks in Fig. 8e and overlain on the seismic image (Fig. 8g) follow the seismic down dipping reflection trend quite accurately. After the tomography, the final NRM displacement is significantly reduced (Fig. $8 \mathrm{~d}$ and $8 \mathrm{f}$ ), and the residual calculated depth error in the red box (Fig. 8h) is reduced, and the reflectors better horizontal aligned. To the left of the red box between CDP 29600 and 29800, above $4.4 \mathrm{~km}$ depth, the tomography could only partially remove the depth error (compare Fig. $8 \mathrm{c}$ and $8 \mathrm{~d}$ ). The reflections in this region could only be aligned with velocities far below the water velocity, indicating that side echoes or cross dipping structures in this region prevent a reliable subsurface velocity determination. To avoid such unrealistic velocity updates during the tomography, a minimum velocity of $1590 \mathrm{~m} \mathrm{~s}^{-1}$ below the seafloor was defined as a precondition. 

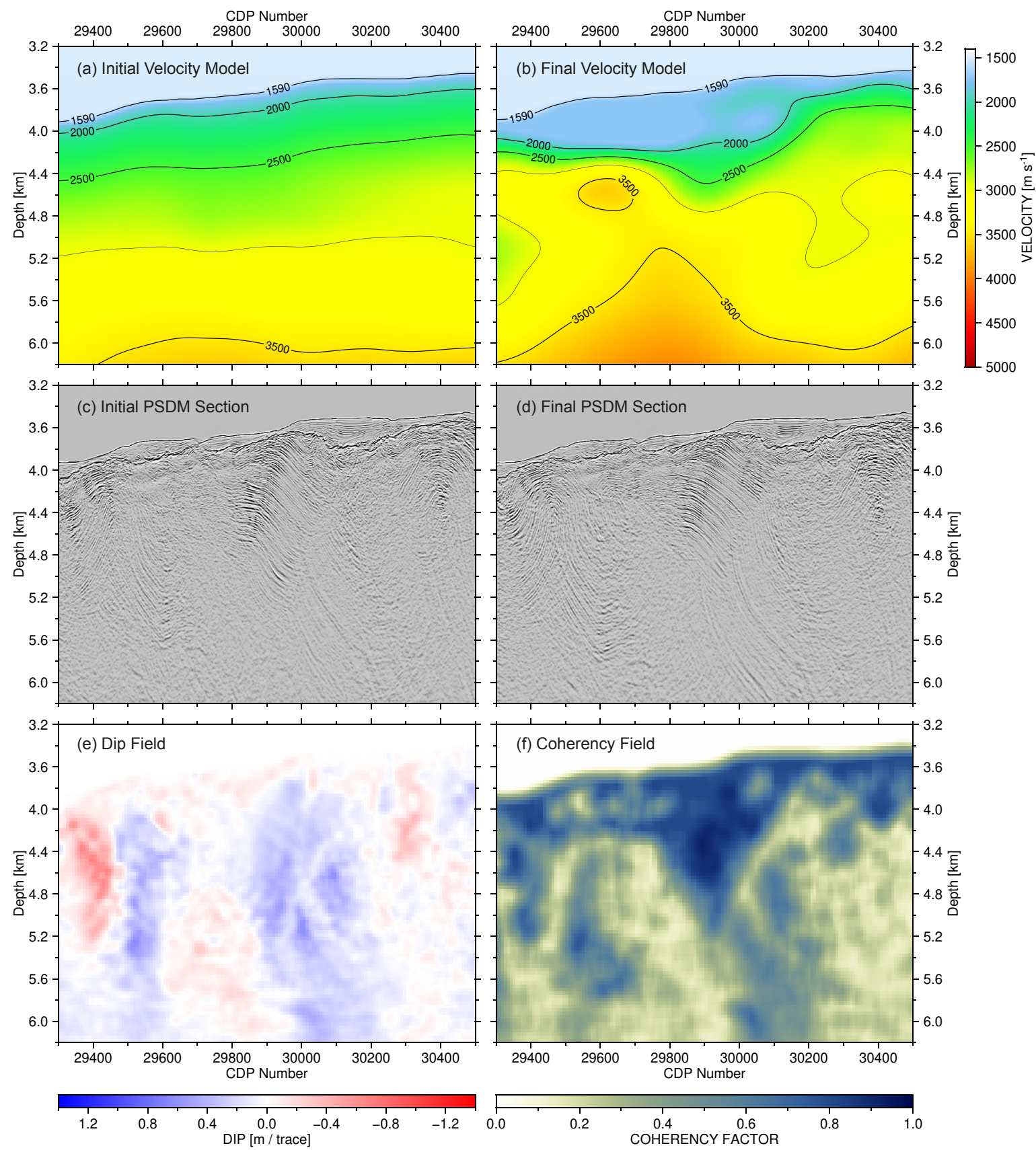

Figure 7. Depth tomography example B in Fig. 3 and Fig. 6b, with CDP ranging from 29300 to 30500. (a) Initial velocity model merged

315 from velocity analysis and wide-angle refraction tomography. (b) Final velocity model after six iterations of NRM based depth tomography and PSDM. (c) PSDM result based on the initial velocity model. (d) PSDM result based on the final velocity model. (e) Reflector dip field calculated from on the final PSDM result. (f) Reflector coherency field calculated from the final PSDM result. Notice the continuity and reflector dip change of the folded sediment layers at a depth of 4.0-4.8 km in (c) and (d) based on the change of the initial velocity and final velocity (a) and (b), respectively. 
https://doi.org/10.5194/se-2021-40

Preprint. Discussion started: 14 April 2021

(C) Author(s) 2021. CC BY 4.0 License.
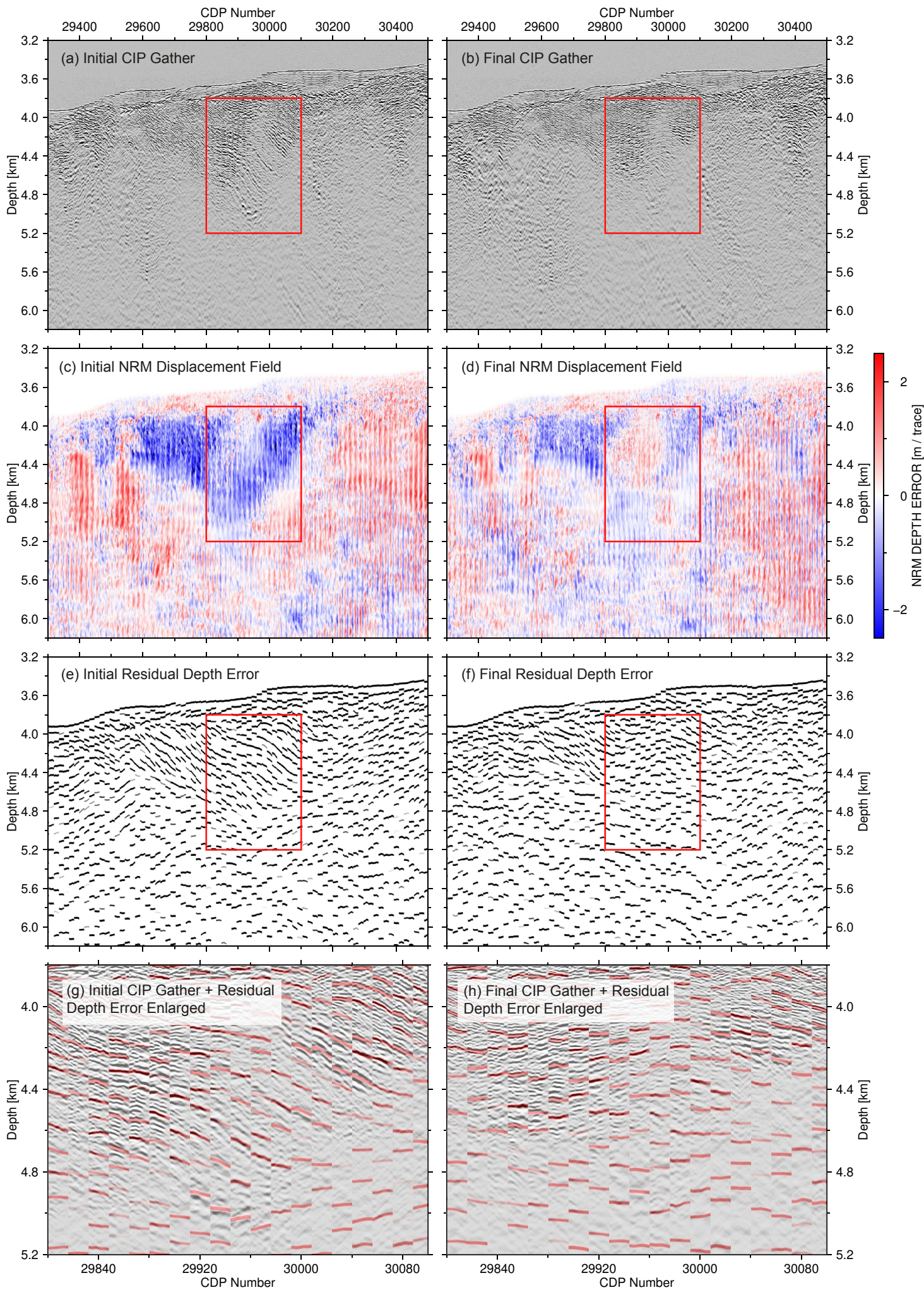
https://doi.org/10.5194/se-2021-40

Preprint. Discussion started: 14 April 2021

(c) Author(s) 2021. CC BY 4.0 License.

(c) (i)

Figure 8. NRM velocity updating of Fig. 7 in CIP domain. (a) CIP gathers based on the initial velocity model. (b) CIP gathers based on the final velocity model. (c) Initial NRM depth shifts in the CIP domain. (d) Final NRM depth shift in CIP domain. (e) RMO picks calculated from the initial NRM displacement field. (f) RMO picks calculated from the final NRM displacement field. Notice that the distinct area of velocity overestimation in the red rectangle in panel (c) has been substantially reduced after the tomography (d). CIP gathers (e) and (f) of the red rectangle from (c) and (d) respectively overlaid by RMO picks. Strong dipping events in the initial CIP gather (g) have mostly been flattened after the final iteration (h).

\subsubsection{Lower Slope NRM Tomography}

In the lower slope region (Fig. 6a, example C), sediment layers are segmented and folded as a result of the regional compressive deformation exerted by the subduction accretion processes. The initial pre-stack depth migration example is shown in Fig. 9c.

330 After the tomography, the final velocity increased by $500 \mathrm{~m} \mathrm{~s}^{-1}$ on average (Fig. 9b), resulting in a significant increase of the velocity gradient compared to the initial velocity model (Fig. 9a). In the final PSDM migration (Fig. 9d), the reflector strength generally increased, and new reflector segments became emphasized compared to the initial migration (Fig. 9c). This is especially evident in the depth range from 6.0 to $6.8 \mathrm{~km}$.

In the initial CIP gathers displayed in Fig. 10a, the reflector distribution appears largely uncorrelated, and no clear trends are visible, particularly within the red box. In the initial NRM displacement field (Fig. 10c), there is a general up dip character that dominates the gathers, as indicated by the red colour, especially within the red rectangle and in the initial residual depth error (Fig. 10e). By increasing the velocities based on the tomography result, this up dip behaviour is reduced both in the final NRM displacement field (Fig. 10d) and in the final residual depth error illustrated by the generally more horizontal alignment of the events (Fig. 10f). In the enlarged view of Fig. 10g and 10h, the general up dip trend has been mostly removed (compare

340 Fig. 10h with 10g). However, local reflector misalignment is still observed, as documented by the local blue colour in the NRM displacement of downward dipping events (Fig. 10d). Even after the tomography, the two local anomalies of four neighbouring CIP gather between CDP 28200 and 28400, at $5 \mathrm{~km}$ and $5.6 \mathrm{~km}$ depth, were not correctly aligned. These local anomalies have a lateral dimension of $\sim 200 \mathrm{~m}$ and are therefore three times shorter than the smallest horizontal scale length smoothing used for the last iteration of the tomography (Tab. 2). 
https://doi.org/10.5194/se-2021-40

Preprint. Discussion started: 14 April 2021

(c) Author(s) 2021. CC BY 4.0 License.
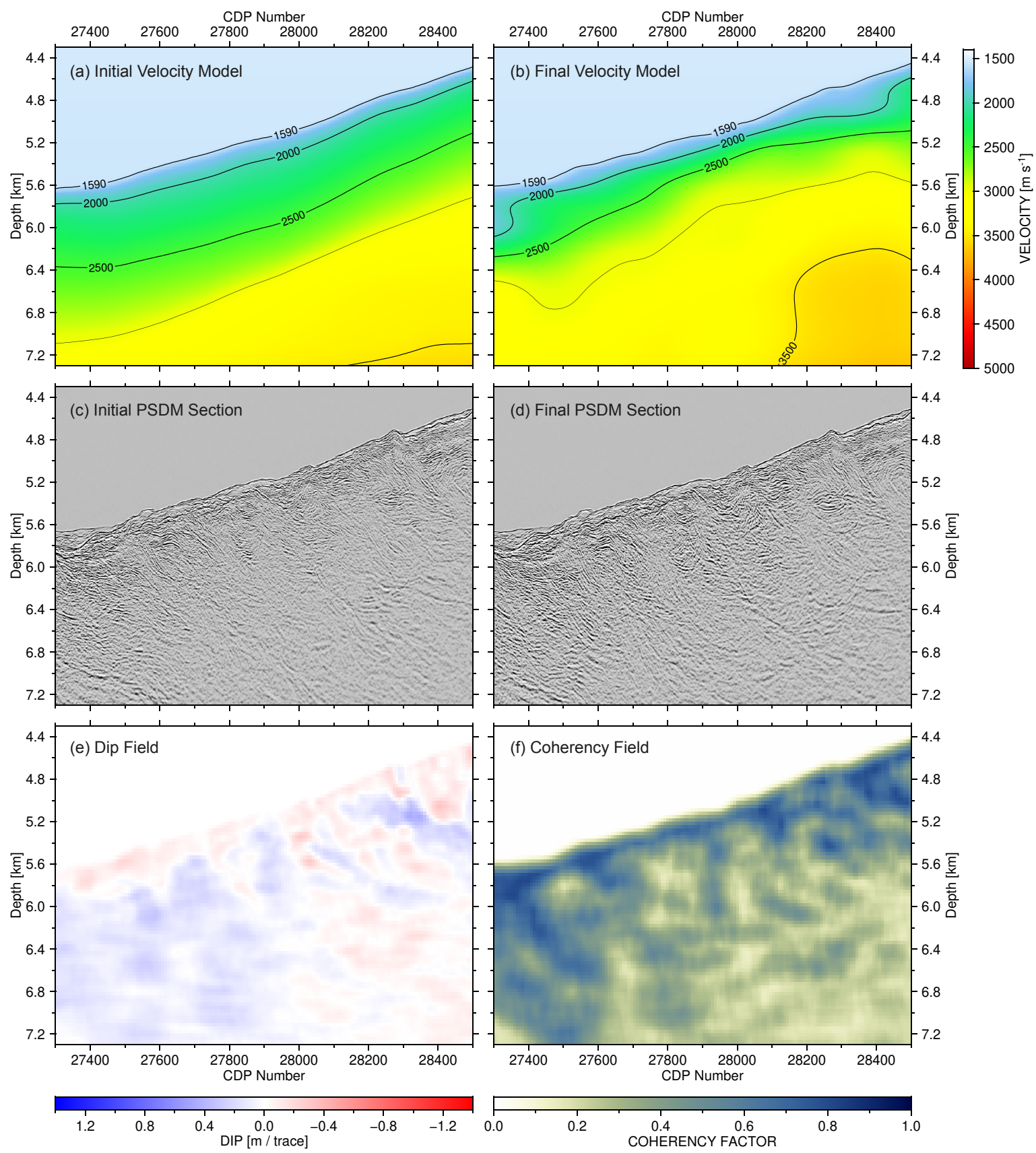

Figure 9. Depth tomography example C in Fig. 3 and Fig. 6a, with CDP ranging from 27200 to 28600. (a) Initial velocity model merged from velocity analysis and wide-angle refraction tomography. (b) Final velocity model after six iterations of NRM based depth tomography and PSDM. (c) PSDM result based on the initial velocity model. (d) PSDM result based on the final velocity model. (e) Reflector dip field calculated from on the final PSDM result. (f) Reflector coherency field calculated from the final PSDM result. Notice that the vertical velocity gradient below the seafloor increased in the final velocity model (b) compared to the initial velocity model (a) with a result of stronger focusing of reflected energy by the PSDM (d) compared to (c). 
https://doi.org/10.5194/se-2021-40

Preprint. Discussion started: 14 April 2021

(c) Author(s) 2021. CC BY 4.0 License.
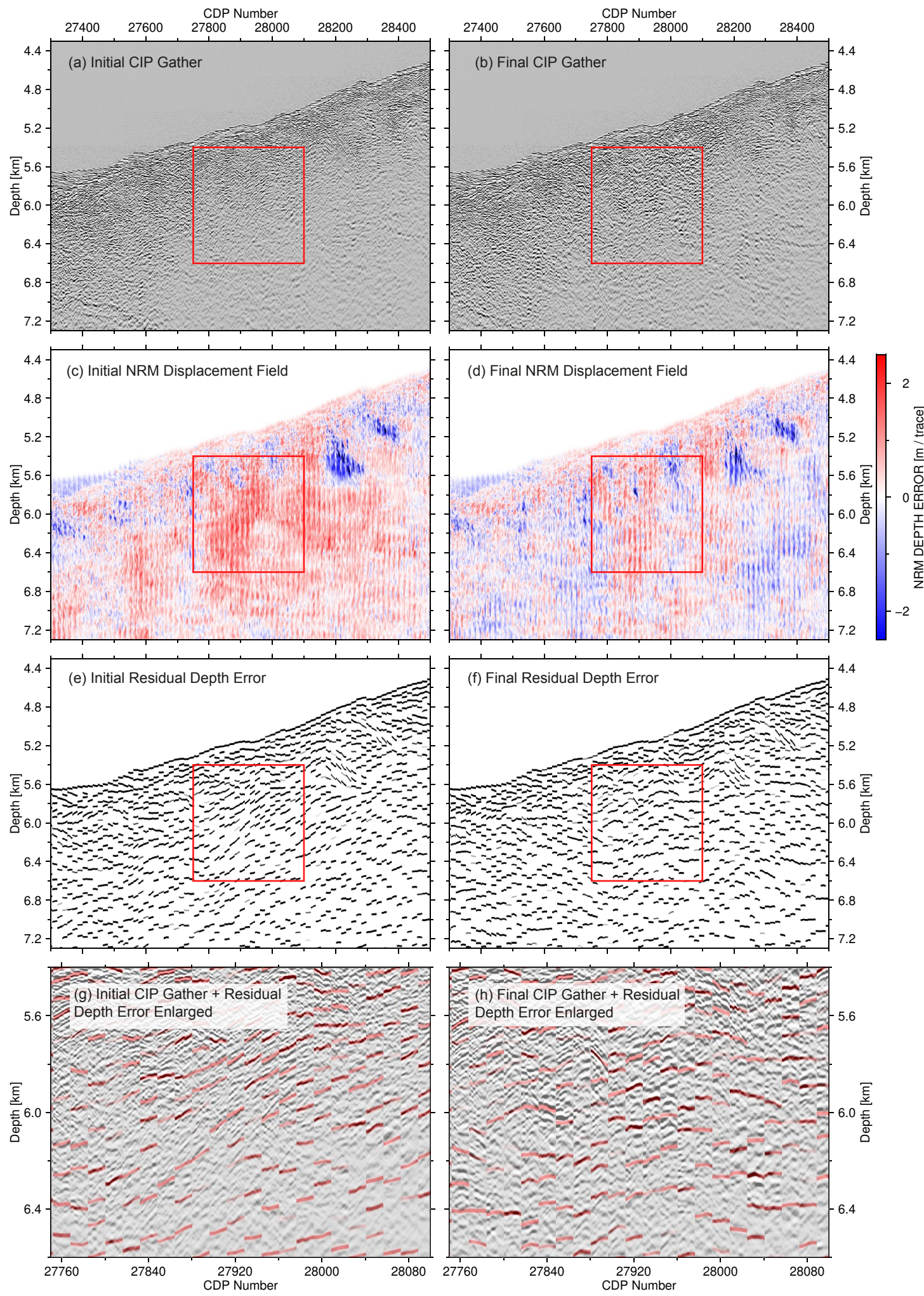
https://doi.org/10.5194/se-2021-40

Preprint. Discussion started: 14 April 2021

(c) Author(s) 2021. CC BY 4.0 License.

(c) (i)

355 Figure 10. NRM velocity updating of Fig. 9 in CIP domain. (a) CIP gathers based on the initial velocity model. (b) CIP gathers based on the final velocity model. (c) Initial NRM depth shifts in the CIP domain. (d) Final NRM depth shift in CIP domain. (e) RMO picks calculated from the initial NRM displacement field. (f) RMO picks calculated from the final NRM displacement field. Notice that the distinct area of velocity underestimation in the red rectangle in panel (c) has been substantially decreased after the tomography (d). CIP gathers (e) and (f) of the red rectangle from (c) and (d) respectively overlaid by RMO picks. Strong dipping events in the initial CIP gather (g) have only partially flattened after the final iteration (h).

\section{Discussion and Results}

\subsection{Iterative Inversion by Scale Length Reduction}

Tomographic inversion works by iterative velocity updating to minimize the observed residual velocity error (Fig. 1). In the CIP gathers, the depth errors distributed over the entire offset range yields the estimation of the interval velocity changes along their ray paths between the source and receiver (Jones, 2010). In grid-based tomography, the updated subsurface velocity model is smoothed by a predefined scale length that decreases in size during the iterations (Tab. 2). To ensure a stable result over all scale lengths, each iteration started with the largest scale length application sequence one up to the desired target scale length iteration sequence. Because the starting velocity was estimated based on a wide-angle tomography (Planert et al., 2010), the first iteration with a large-scale length did not experience significant velocity corrections. The higher the iteration number with corresponding reduced scale length, the more pronounced were the velocity updates observed. After the sixth iteration, the velocity updates were stopped because in subsequent iterations, the fluctuations of velocity changes could no longer be related to subsurface structures.

Importantly, each velocity update to the velocity model will change the ray paths. The best solution is to slowly update the velocity in an iterative approach and not significantly disturb the pattern of the ray paths in the following iteration. Depending on the complexity of the geological structure and the approximated velocity deviation from the velocity model to the real subsurface geophysical system, the maximum allowed velocity update varies from case to case. In our cases, we set the maximum velocity update to $10-15 \%$ of the current velocity model for each iteration, which is a compromise between computation time and result quality and stability. While a situation could occur where the local velocity update is more than $15 \%$ of the current velocity model, a customized damping factor should be assigned to reduce the maximum velocity update, or the previous iteration needs to run twice. In comparison, if the update is smaller than $3 \%$, the inversion can be stopped or continued up to smaller grid size. A perfect final tomography result is never reachable due to the approximations of wave propagation. Qualitative control will give a comparison of the reflectors horizontal alignment in the CIP gather with respect to the previous iteration or initial iteration. To produce a final image, residual move-out correction of the smoothed NRM displacement field could always be applied directly to flatten all the remaining dipping events in the CIP gathers to maximize the quality of the migration CIP stacked image without additional changes to the velocity model (Perez and Marfurt, 2008). 
https://doi.org/10.5194/se-2021-40

Preprint. Discussion started: 14 April 2021

(c) Author(s) 2021. CC BY 4.0 License.

(c) (i)

\subsection{Layer based vs. Grid-based Tomography}

Historically, two basic tomography schemes exist, the layer-based and the grid-based schemes, while hybrid schemes combine the advantages of both strategies. For a geological setting where a strong impedance interface limits the boundary of the medium property and the velocity change, a layer-based tomographic inversion with a prejudged bias information will often result in a good tomographic solution. The RMO of CIP-gathers is manually picked along strong continuous reflections defined as horizons to update the velocity for each layer in a top to bottom approach. For each layer, a vertical gradient can be predefined, whereas lateral variations are determined by the tomography itself. A successful and detailed application of this strategy in a subsection of the New Jersey shelf (Riedel et al., 2019) could be validated by only small depth misfits between horizons of the depth migrated profiles and borehole core data. In that case, the gently-dipping reflection sequence was related to relative changes in sea level, where the individual layers do not show a strong vertical gradient in the borehole sonic log.

For sediments with a seismic velocity distribution disassociated from the impedance interfaces, a grid-based tomography will provide a more realistic result compared to layer-based schemes. Because many reflectors in the CIP-gathers must be picked, automatic picking procedures will be necessary. A comparison between layer-based and grid-based tomography (Sugrue et al., 2004) with dense continuous automatic slowness picking (Hardy, 2004) of residual depth errors in the CIP-

400 gather domain shows a more realistic, smoothly-varying velocity field in the grid-based approach, where the sharpness of velocity interfaces depends mainly on the smallest vertical scale length used during the tomography.

In a situation where sediment below an undulating interface with a significant velocity contrast must be imaged, the sediment below this interface will also show an undulating behaviour if the horizontal cell grid size is greater than the reflector undulations. In this situation, a hybrid model is useful to define a constrained horizon in the grid-based tomography that follows the reflector undulations (Jones et al., 2007). If the velocity variation is strongly controlled by local medium property changes near the seafloor, e.g., shallow local low-velocity areas underlying canyon infills, a hybrid model with predefined velocity values is more efficient than trying to solve isolated velocity anomalies by reducing the scale length of the tomography (Fruehn et al., 2008).

Based on the a priori knowledge we gained for profile BGR06-313 after the initial migration, a layer-based approach would

410 be inadequate on a regional scale. The sediments are significantly tilted and folded within the accretionary wedge, and no continuous reflections could be tracked as a well-defined horizon (Fig. 7c and 9c). Even if a detailed small-scale velocity model for such complex folded structures is not resolvable, a generally vertical and horizontal velocity gradient obtainable through a grid-based approach can provide valuable information on large-scale processes like compaction and dewatering within the wedge. Additionally, according to the principle of grid-based tomography, a greater amount of detailed input 415 information will improve the tomographic result. A layer-based scheme, which strips off the sediment from top to bottom, will neglect important constraining information provided from small-scale structures beneath. 
https://doi.org/10.5194/se-2021-40

Preprint. Discussion started: 14 April 2021

(c) Author(s) 2021. CC BY 4.0 License.

(c) (i)

\subsection{Quality vs. Quantity of Depth Error Picks}

With a grid-based tomography, a large volume with a high spatial density of the residual depth errors needs to be picked in order to maximize the result's reliability (Jones, 2003). Once there is a conflict occurring between some of the equations in one grid cell, the minority picks (which could be good or bad) will be rejected by the tomography algorithm in order to get a stable and self-consistent result. Unrealistic picks have an unfavourable effect on the tomographic results when they become the majority. Several approaches should be applied to avoid this from happening, depending on the origin of the unreliable picks. For massive three-dimensional scattered crustal events below a basement structure, we digitized a horizon as a lower boundary of the available residual move-out picks (Fig. 4, 5a, and 5e). To attenuate side echoes, residual multiple energy, or cross-cutting events in the CIP-gathers (e.g., Fig. 2d, RMO_Pick_2) resulting in unexpected low velocities, we applied a dipfilter prior to the NRM displacement calculation. To separate regions of reliable and less reliable picks, the reflector coherency was calculated for the PSDM profile after each iteration. This coherency information was used as a weighting factor to the picks to distinguish whether the residual move-out originated from a well-stratified sediment environment or from a rough, discontinuous structure (Fig. 7d and 7f).

\subsection{Grid-Based Tomography Result}

The Java accretionary margin is a localized end member of a fold-and-thrust belt environment, with a complex geological background and small-scale structural heterogeneities. Along the lower and middle slope, strongly folded and fractured strata with limited spatial extents make the construction of a detailed layer-based macro model unachievable. Due to the high reflectivity in the upper $4 \mathrm{~km}$ below the seafloor, a grid-based tomography based on closely spaced (100 $\mathrm{m}) \mathrm{CIP}$-gathers with pure data-driven depth error analyses provides the best solution. The initial subsurface velocity model (Fig. 11a) is a merge of manually heavily smoothed velocities estimated by interactive velocity picking and a smoothed version of the 2-D refraction seismic travel time tomography. The transition between the two velocity fields is marked by a semi-transparent grey line in Fig. 11a. Close to the trench axis and the uplifted sediment ridge (CDP 25500-27500), a velocity reduction of up to $10 \%$ (Fig. 11c) indicates a low degree of compaction in the upper deformed sediment layers. Along the lower and upper slope (Fig. 11c, CDP 27500-32000), the opposite is observed. Aside from local sediment basins with a velocity decrease of up to $10 \%$, a significant velocity increase of more than $20 \%$ in the upper $500 \mathrm{~m}$ indicates a longer history of compaction. Additionally, the complex reflectivity pattern (e.g., Fig. 9d) represents a long history of compressional tectonic deformation that manifests itself in thrust ridges at the seafloor and intervening sediment basins. The complex and laterally-disrupted reflectivity that has resulted from this history of deformation would make a conventional migration velocity analysis with sparse analysis locations extremely difficult. 
https://doi.org/10.5194/se-2021-40

Preprint. Discussion started: 14 April 2021

(c) Author(s) 2021. CC BY 4.0 License.
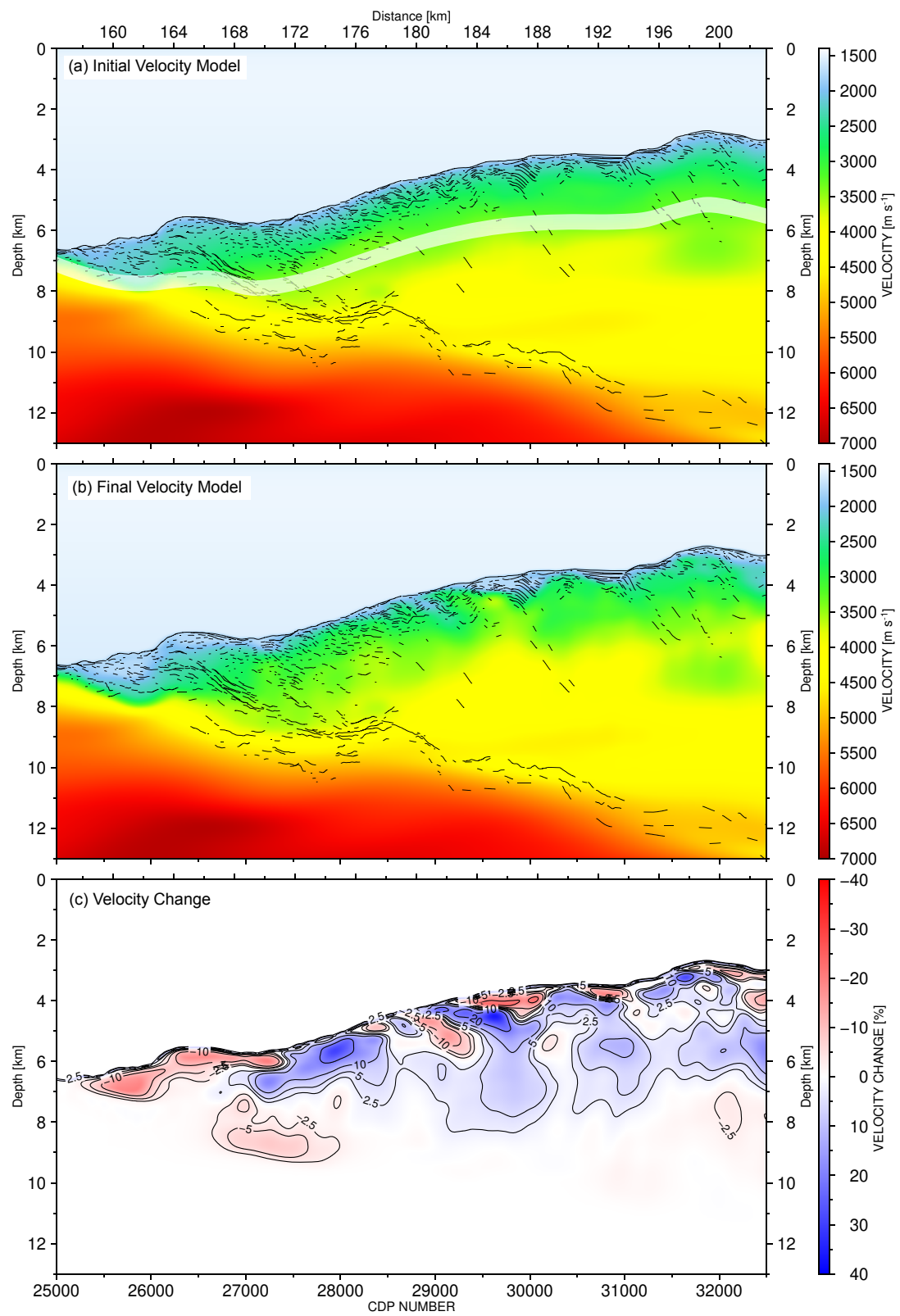

450 Figure 11. (a) The initial velocity model merged from the multi-channel seismic velocity analysis (above the white transparent band) and the wide-angle velocity model (below the white transparent band). The line drawing is based on the final PSDM image. (b) The final velocity model calculated from six iterations of the ray-based topographic velocity inversion. (c) The velocity change from the initial to the final model. 
https://doi.org/10.5194/se-2021-40

Preprint. Discussion started: 14 April 2021

(C) Author(s) 2021. CC BY 4.0 License.
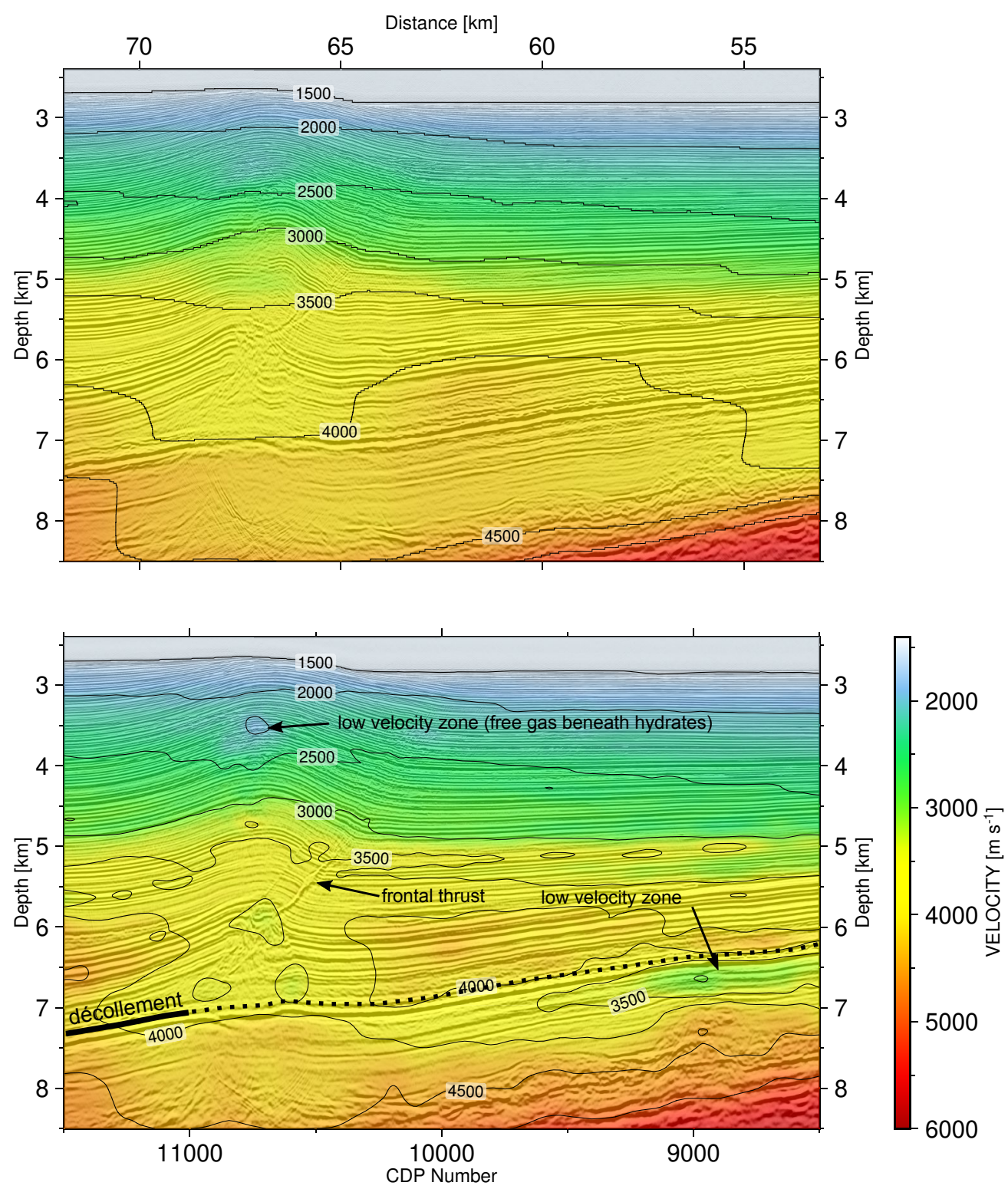

Figure 12. Depth tomography with NRM velocity updating and PSDM for moderate complex structures. (a) Depth converted pre-stack time migration and the initial velocity model. (b) PSDM result and velocity model estimated by grid-based depth tomography and updated by NRM displacement field. Notice that the velocity variations follow the reflection structure without predefined horizons. Even a not predefined bottom simulated reflector at $3.5 \mathrm{~km}$ depth at CDP 10750 shows a velocity decrease due to fluid flow. 
https://doi.org/10.5194/se-2021-40

Preprint. Discussion started: 14 April 2021

(c) Author(s) 2021. CC BY 4.0 License.

In moderate layered subsurface structures, a layer-based tomography is commonly the first choice where vertical gradients in each layer are mostly ignored. An advantage of a grid-based tomography is the estimation of both vertical and lateral velocity gradients, which are the result of horizontal and vertical stress changes and dewatering processes. Additionally, the existence of fluid escape structures or free gas beneath a bottom simulating reflector (BSR) can first be confirmed by velocity anomalies and are therefore not easy to be defined a priori in a layered model. This was verified with our early experiences of the NRM warping method initially tested in a moderately complex layered subsurface structure. A pre-stack time migration converted to the depth of the MCS profile PEG09-23 offshore New Zealand's southern Hikurangi margin is displayed in Fig. 12a. These data are overlain by the smooth background velocity model without significant velocity inversions. The result of the NRM depth error analysis followed by the grid-based tomography in Fig. 12b (Crutchley et al., 2020) shows clear horizon-based velocity changes. At a depth between $6 \mathrm{~km}$ and $7 \mathrm{~km}$, and between CDP 8500 and 9500, a low velocity region is observed below a gently-dipping horizon that ultimately becomes the subduction décollement toward the left-hand side of the image (Fig. 12b). The gradual reduction of the low velocity region with increasing proximity to the frontal thrust fault has been interpreted by Crutchley et al. (2020) as the result of more effective upward drainage closer to the fault. At the near-surface structure at $3.5 \mathrm{~km}$ depth at CDP 10750 (Fig. 12b), a local low velocity zone is detected. This low velocity is interpreted as a gas cloud below an observed BSR with negative polarity. By detecting and accounting for this low velocity free gas zone in the shallow sub-surface, there is a significant improvement in the continuity of reflectors in the deeper structures (Fig. 12b) compared to the initial image of Fig. 12a.

A broader implication of this work result is that a less accurate velocity model could lead to erroneous tectonic interpretations based on mispositioning of reflector elements. For the example of the initial imaging in Fig. 7c, it would have been tempted to have interpreted the existence of a developing back-thrust within this fold to explain the abrupt change in dip along the tilted sediment layers. By the improved imaging (Fig.7b), it a clear that this is just an artefact of the PSDM based on a less accurate velocity field.

\subsection{Alternative warping methods to NRM: Dip Field by Plane Wave Destructive (PWD) Filter}

A common method to calculate a dip field of a seismic section is realized by the plane wave destruction (PWD) filter (Claerbout, 1992; Xue et al., 2019). To compare the NRM with the PWD method, we applied the same calculations of Fig. 2 (with the NRM method) to the same events but using a PWD filter (Fig. 13). The most obvious differences between the two approaches can be seen on the flattened corrected gathers by comparing Fig. 2c and 13c.

The NRM approach was originally developed to calculate a smooth vertical displacement field between sections of 3D timelapse seismic data. The PWD method, by contrast, lacks this vertical and horizontal smoothness, which results in less correct results - most clearly seen on the two horizontal events. In order to diminish very small-scale local velocity undulations but leave the general trend of the velocity variation untouched, a smoothing procedure of the depth error prior to tomography is necessary for any geological environment. A single trace boxcar filter will smooth out the outliers in the depth domain. A spatial boxcar filter can be applied in the CIP domain and/or in the common offset domain to gain more spatial consistency in 
https://doi.org/10.5194/se-2021-40

Preprint. Discussion started: 14 April 2021

(c) Author(s) 2021. CC BY 4.0 License.

(c) (i)

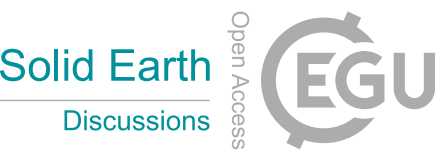

the CIP-gathers or along the profile, respectively. An alternative method could be dynamic image warping (DIW), which is able to calculate rapid and large shifts, both in time/depth and in space, and overcomes the restrictions of limited shifts due to time/depth windowing used by cross-correlation methods (Hale, 2013; Zhang et al., 2014).
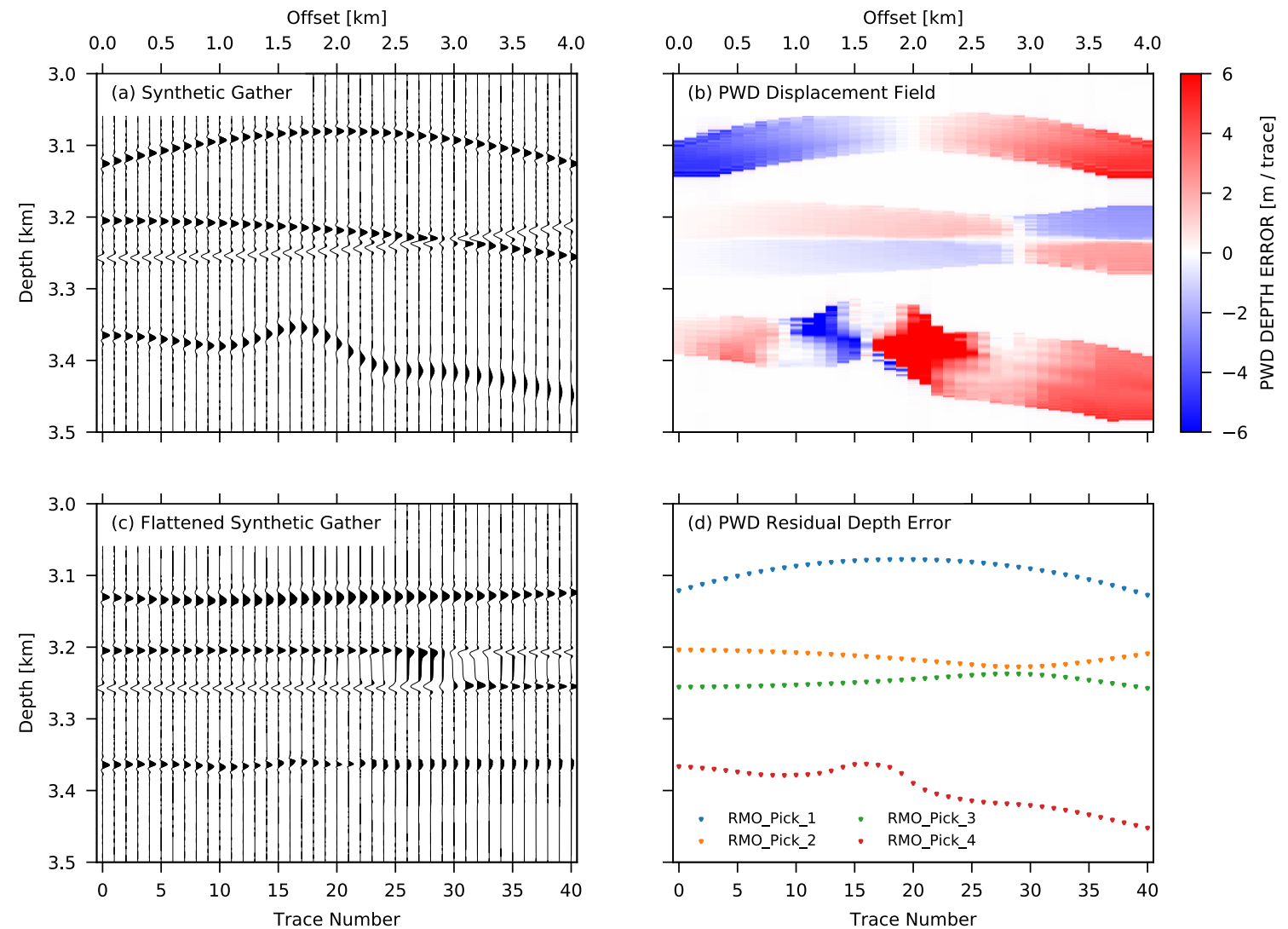

Figure 13. (a) Simulated complex geological situations that would be frequently seen in pre-stack depth migrated (PSDM) common-imagepoint (CIP) domain in comparison to Fig 2. A symmetrical diffraction, two interfering primaries with opposite polarity, and a non-linear local static undulation, including frequency versus offset signal variations. (b) The PWD displacement of gather (a) calculated from trace $\mathrm{n}$ to the following trace $(n+1)$. Note the polarity change compared to Fig. $2 b$ because of opposite trace order calculations. (c) Application of the displacement correction from (b) to the gather of (a). (d) Residual move-out picks calculated by recursive summation of the relative depth errors (b) at predefined depths to get the cumulative depth error. Only minor depth error differences are observed between the PWD and NRM calculation in Fig. 2 d. 
https://doi.org/10.5194/se-2021-40

Preprint. Discussion started: 14 April 2021

(c) Author(s) 2021. CC BY 4.0 License.

(c) (1)

\section{Conclusions}

510 We have successfully performed a grid-based reflection tomography with depth error estimations by Non-Rigid Matching (NRM) depth warping. Our results from analysis of NRM warping limitations in a synthetic CIP-gather, and a real data application from simple to complex sediment structures across the Java trench, revealed the following:

The NRM displacement field estimation in a relative referenced scheme between neighbouring traces is limited by coherent noise, intersecting events, or side echoes on 2D profiles. An alternative to NRM warping is a plane-wave

515 destruction filter (PWD), but this method has reduced smoothness and accuracy.

The NRM method could be applied, as a purely data-driven method, to multi-channel seismic common image point gathers in the depth domain to estimate the residual depth error displacement field of any curvature. To calculate the relative depth error values in a gather along a predefined depth slice, a recursive depth variant correction followed by a cumulative summation of the individual displacements will yield the desired depth error information for the gather. Since the reflection

520 depth tomography is capable of handling any kind of reflected arrival information without the restriction of curvature, the combination of high-density NRM displacement fields in conjunction with tomography is an ideal combination for complex subsurface structures.

On profile BGR06-313, across the Java trench, the initial velocity field is derived from manually picked velocities at the near seafloor surface merged with an existing wide aperture tomographic result. Based on the NRM tomographic results, the 525 near surface velocities are significantly reduced close to the trench axis and in the first uplifted sediment ridge by more than $10 \%$. Further inboard, along the lower and upper slope, local low velocity sediment basins were identified. The velocities in the deeper complex of accreted sediment, where reflector continuity is low, increased from the starting model by up to $20 \%$. The higher velocities and the highly-deformed stratigraphy suggest, intuitively, that these sediments have experienced greater long-term compaction than the sediments closer to the toe of the wedge. All seismic images improve by increasing 530 reflection strength, sharpness, more continuity, and less depth error due to more accurate velocities. 
https://doi.org/10.5194/se-2021-40

Preprint. Discussion started: 14 April 2021

(c) Author(s) 2021. CC BY 4.0 License.

(c) (i)

Authors contributions. YX and DK performed the computations and are responsible for the main processing. HK helped to strengthen the overall scope and added to interpretational aspects and the discussion of the presented results. MS made the data available and was responsible for the navigation and geometry processing. YX wrote the article, and all authors contributed equally to proofreading and final preparation of the manuscript.

Data availability. The raw and final results are available upon reasonable request.

Competing interest. The authors declare that they have no competing interests.

\section{Financial support}

R/V SONNE cruise SO190 and the SINDBAD project were funded by the German Federal Ministry of Education and Research 540 (BMBF) under grants 03G0190A and 03G0190B. Y. Xia acknowledges funding from the China Scholarship Council (grant 201506400067).

\section{Acknowledgments}

R/V SONNE cruise SO190 and the SINDBAD project were funded by the German Federal Ministry of Education and Research (BMBF) under grants 03G0190A and 03G0190B. Y. Xia acknowledges funding from the China Scholarship Council (grant 545 201506400067). Bathymetric data from R/V SONNE cruise SO190 can be requested through the German Bundesamt für Seeschifffahrt und Hydrographie (BSH; http://www.bsh.de). Seismic reflection line SO190 BGR06-313 is stored at the Bundesanstalt für Geowissenschaften und Rohstoffe (BGR) and can be requested through the Geo-Seas data portal (https://geoseas.bgr.de/bgrwebapp/SO190/BGR06-313_mig_oem.xml). The seismic data were processed with Schlumberger's Omega2 seismic processing suite OMEGA and Seismic Unix - open-source software package for seismic research and 550 processing, Center for Wave Phenomena, Colorado School of Mines. Bathymetry and seismic images are plotted by the Generic Mapping Tools (GMT) and Matplotlib. 
https://doi.org/10.5194/se-2021-40

Preprint. Discussion started: 14 April 2021

(c) Author(s) 2021. CC BY 4.0 License.

(c) (i)

\section{References}

Aarre, V.: Estimating 4D velocity changes and contact movement on the Norne field, SEG Tech. Progr. Expand. Abstr., 25,

3115-3119, https://doi.org/10.1190/1.2370175, 2006.

Aarre, V.: On the presence, and possible causes, of apparent lateral shifts below the Norne reservoir, 78th Soc. Explor. Geophys. Int. Expo. Annu. Meet. SEG 2008, 3174-3178, 2018.

Audebert, F. and Diet, J.-P.: A focus on focusing, in: 52nd EAEG Meeting, Copenhagen, 1990.

Audebert, F., Diet, J.-P., Guillaume, P., Jones, I. F., and Zhang, X.: CRP-Scans: 3D PreSDM velocity analysis via zero-

560 offset tomographic inversion, in: SEG Technical Program Expanded Abstracts 1997, Society of Exploration Geophysicists, 1805-1808, 1997.

Bishop, T. N., Bube, K. P., Cutler, R. T., Langan, R. T., Love, P. L., Resnick, J. R., Shuey, R. T., Spindler, D. A., and Wyld, H. W.: Tomographic determination of velocity and depth in laterally varying media, 50, 903-923, https://doi.org/10.1190/1.1441970, 1985.

565 Claerbout, J. F.: Earth soundings analysis: Processing versus inversion, Blackwell Scientific Publications London, 1992. Collot, J. Y., Ribodetti, A., Agudelo, W., and Sage, F.: The South Ecuador subduction channel: Evidence for a dynamic mega-shear zone from 2D fine-scale seismic reflection imaging and implications for material transfer, J. Geophys. Res. Solid Earth, 116, 1-20, https://doi.org/10.1029/2011JB008429, 2011.

Crutchley, G. J., Klaeschen, D., Henrys, S. A., Pecher, I. A., Mountjoy, J. J., and Woelz, S.: Subducted sediments, upperplate deformation and dewatering at New Zealand's southern Hikurangi subduction margin, Earth Planet. Sci. Lett., 530, 115945, https://doi.org/10.1016/j.eps1.2019.115945, 2020.

Dix, C. H.: Seismic velocities from surface measurements, 20, 68-86, 1955.

Fomel, S.: Applications of plane-wave destruction filters, 67, 1946-1960, 2002.

Fruehn, J., Jones, I. F., Valler, V., Sangvai, P., Biswal, A., and Mathur, M.: Resolving near-seabed velocity anomalies: Deep water offshore south east India, 78th Soc. Explor. Geophys. Int. Expo. Annu. Meet. SEG 2008, 73, 3285-3289, 2018.

Górszczyk, A., Operto, S., Schenini, L., and Yamada, Y.: Crustal-scale depth imaging via joint full-waveform inversion of ocean-bottom seismometer data and pre-stack depth migration of multichannel seismic data: A case study from the eastern Nankai Trough, 10, 765-784, https://doi.org/10.5194/se-10-765-2019, 2019.

Gras, C., Dagnino, D., Jiménez-Tejero, C. E., Meléndez, A., Sallarès, V., and Ranero, C. R.: Full-waveform inversion of 580 short-offset, band-limited seismic data in the Alboran Basin (SE Iberia), 10, 1833-1855, 2019.

Guitton, A. and Verschuur, D. J.: Adaptive subtraction of multiples using the L1-norm, Geophys. Prospect., 52, 27-38, 2004. Hale, D.: A method for estimating apparent displacement vectors from time-lapse seismic images, Soc. Explor. Geophys. 77th SEG Int. Expo. Annu. Meet. SEG 2007, 74, 2939-2943, 2007.

Hale, D.: Dynamic warping of seismic images, 78, S105-S115, https://doi.org/10.1190/GEO2012-0327.1, 2013.

Hall, S. A.: A methodology for 7D warping and deformation monitoring using time-lapse seismic data, 71, 
https://doi.org/10.5194/se-2021-40

Preprint. Discussion started: 14 April 2021

(c) Author(s) 2021. CC BY 4.0 License.

(c) (i)

https://doi.org/10.1190/1.2212227, 2006.

Hampson, D.: Inverse velocity stacking for multiple elimination, J. Can. Soc. Explor. Geophys., 22, 44-55, 1986.

Han, S., Bangs, N. L., Carbotte, S. M., Saffer, D. M., and Gibson, J. C.: Links between sediment consolidation and Cascadia megathrust slip behaviour, Nat. Geosci., 10, 954-959, https://doi.org/10.1038/s41561-017-0007-2, 2017.

Hardy, P.: High resolution tomographic MVA with automation, in: 66th EAGE Conference \& Exhibition, cp--133, 2004.

Horn, B. K. P. and Schunck, B. G.: Determining optical flow, Artif. Intell., 17, 185-203, https://doi.org/10.1016/0004-

3702(81)90024-2, 1981.

Jones, I. F.: A review of 3D PreSDM model building techniques, First Break, 21, 2003.

Jones, I. F.: Tutorial: Velocity estimation via ray-based tomography, First Break, 28, 45-52, 2010.

595 Jones, I. F., Sugrue, M. J., and Hardy, P. B.: Hybrid gridded tomography, First Break, 25, 2007.

Jones, I. F., Ibbotson, K., Grimshaw, M., and Plasterie, P.: Prestack Depth Migration and Velocity Model Building, edited by: Jones, I. F., Bloor, R. I., Biondi, B. L., and Etgen, J. T., Society of Exploration Geophysicists, 897-906 pp., https://doi.org/10.1190/1.9781560801917, 2008.

Kosloff, D., Sherwood, J., Koren, Z., Machet, E., and Falkovitz, Y.: Velocity and interface depth determination by

600 tomography of depth migrated gathers, 61, 1511-1523, 1996.

Levitus, S.: Climatological Atlas of the World Ocean, Eos, Trans. Am. Geophys. Union, 64, 962-963, https://doi.org/https://doi.org/10.1029/EO064i049p00962-02, 1983.

Li, J., Shillington, D. J., Saffer, D. M., Bécel, A., Nedimović, M. R., Kuehn, H., Webb, S. C., Keranen, K. M., and Abers, G. A.: Connections between subducted sediment, pore-fluid pressure, and earthquake behavior along the Alaska megathrust,

605 Geology, 46, 299-302, https://doi.org/10.1130/G39557.1, 2018.

Lüschen, E., Müller, C., Kopp, H., Engels, M., Lutz, R., Planert, L., Shulgin, A., Djajadihardja, Y. S., Lueschen, E., Mueller, C., Kopp, H., Engels, M., Lutz, R., Planert, L., Shulgin, A., and Djajadihardja, Y. S.: Structure, evolution and tectonic activity of the eastern Sunda forearc, Indonesia, from marine seismic investigations, 508, 6-21, https://doi.org/10.1016/j.tecto.2010.06.008, 2011.

610 MacKay, S. and Abma, R.: Imaging and velocity estimation with depth-focusing analysis, 57, 1608-1622, 1992.

Neidell, N. S. and Taner, M. T.: Semblance and other coherency measures for multichannel data, 36, 482-497, 1971.

Nickel, M., Sønneland, L., and Geco-prakla, S.: Non-rigid matching of migrated time-lapse seismic SEG 1999 Expanded Abstracts SEG 1999 Expanded Abstracts, 1999.

Pappu, S., Gold, S., and Rangarajan, A.: A Framework for Non-rigid Matching and Correspondence., Adv. Neural Inf.

615 Process. Syst., 795-801, 1996.

Perez, G. and Marfurt, K. J.: Warping prestack imaged data to improve stack quality and resolution, 73, 1-7, https://doi.org/10.1190/1.2829986, 2008.

Planert, L., Kopp, H., Lüschen, E., Mueller, C., Flueh, E. R., Shulgin, A., Djajadihardja, Y., and Krabbenhoeft, A.: Lower plate structure and upper plate deformational segmentation at the Sunda-Banda arc transition, Indonesia, J. Geophys. Res. 
https://doi.org/10.5194/se-2021-40

Preprint. Discussion started: 14 April 2021

(c) Author(s) 2021. CC BY 4.0 License.

(c) (i)

620 Solid Earth, 115, 1-25, https://doi.org/10.1029/2009JB006713, 2010.

Reiche, S. and Berkels, B.: Automated stacking of seismic reflection data based on nonrigid image matching, 83, V171V183, https://doi.org/10.1190/geo2017-0189.1, 2018.

Rickett, J. E. and Lumley, D. E.: Cross-equalization data processing for time-lapse seismic reservoir monitoring: A case study from the Gulf of Mexico, 66, 1015-1025, 2001.

625 Riedel, M., Reiche, S., Aßhoff, K., and Buske, S.: Seismic depth imaging of sequence boundaries beneath the New Jersey shelf, Mar. Geophys. Res., 40, 17-32, https://doi.org/10.1007/s11001-018-9360-9, 2019.

Robinson, E. A. and Treitel, S.: Geophysical signal analysis, Society of Exploration Geophysicists, 2000.

Sambolian, S., Operto, S., Ribodetti, A., Tavakoli, B., and Virieux, J.: Parsimonious slope tomography based on eikonal solvers and the adjoint-state method, Geophys. J. Int., 218, 456-478, https://doi.org/10.1093/gji/ggz150, 2019.

630 Shiraishi, K., Moore, G. F., Yamada, Y., Kinoshita, M., Sanada, Y., and Kimura, G.: Seismogenic zone structures revealed by improved 3-D seismic images in the Nankai Trough off Kumano, Geochemistry, Geophys. Geosystems, 20, 2252-2271, 2019.

Sripanich, Y., Fomel, S., Stovas, A., and Hao, Q.: 3D generalized nonhyperboloidal moveout approximation, 82, C49--C59, 2017.

635 Sripanich, Y., Fomel, S., Trampert, J., Burnett, W., and Hess, T.: Probabilistic moveout analysis by time warping, 85, U1U20, https://doi.org/10.1190/geo2018-0797.1, 2020.

Stork, C.: Reflection tomography in the postmigrated domain, 57, 680-692, https://doi.org/10.1190/1.1443282, 1992.

Sugrue, M., Jones, I. F., Evans, E., Fairhead, S., and Marsden, G.: Enhanced velocity estimation using gridded tomography in complex chalk, Geophys. Prospect., 52, 683-691, 2004.

640 Tomar, G., Singh, S. C., and Montagner, J.-P.: Sub-sample time shift and horizontal displacement measurements using phase-correlation method in time-lapse seismic, Geophys. Prospect., 65, 407-425, 2017.

Van Trier, J. A.: Tomographic determination of structural velocities from depth-migrated seismic data, Stanford University, 1990.

Verschuur, D. J., Berkhout, A. J., and Wapenaar, C. P. A.: Adaptive surface-related multiple elimination, 57, 1166-1177,

645 https://doi.org/10.1190/1.1443330, 1992.

Wolberg, G.: Digital image warping, IEEE computer society press Los Alamitos, CA, 1990.

Xue, Z., Zhang, H., Zhao, Y., and Fomel, S.: Pattern-guided dip estimation with plane-wave destruction filters, Geophys.

Prospect., 67, 1798-1810, 2019.

Yilmaz, Ö.: Seismic data analysis: Processing, inversion, and interpretation of seismic data, Society of exploration

650 geophysicists, 2001.

Zhang, D., Wang, X., Huang, Y., and Schuster, G.: Warping for trim statics, in: SEG Technical Program Expanded Abstracts 2014, Society of Exploration Geophysicists, 3946-3950, 2014. 